\title{
LS3MIP (v1.0) contribution to CMIP6: the Land Surface, Snow and Soil moisture Model Intercomparison Project - aims, setup and expected outcome
}

Bart van den Hurk ${ }^{1}$, Hyungjun Kim ${ }^{2}$, Gerhard Krinner ${ }^{3}$, Sonia I. Seneviratne ${ }^{4}$, Chris Derksen ${ }^{5}$, Taikan Oki ${ }^{2}$, Hervé Douville $^{6}$, Jeanne Colin ${ }^{6}$, Agnès Ducharne ${ }^{24}$, Frederique Cheruy ${ }^{7}$, Nicholas Viovy ${ }^{8}$, Michael J. Puma ${ }^{9}$, Yoshihide Wada ${ }^{10}$, Weiping Li ${ }^{11}$, Binghao Jia ${ }^{12}$, Andrea Alessandri ${ }^{13}$, Dave M. Lawrence ${ }^{14}$, Graham P. Weedon ${ }^{15}$, Richard Ellis ${ }^{16}$, Stefan Hagemann ${ }^{17}$, Jiafu Mao ${ }^{18}$, Mark G. Flanner ${ }^{19}$, Matteo Zampieri ${ }^{20}$, Stefano Materia ${ }^{20}$, Rachel M. Law ${ }^{21}$, and Justin Sheffield ${ }^{22,23}$

${ }^{1}$ KNMI, De Bilt, the Netherlands

${ }^{2}$ Institute of Industrial Science, the University of Tokyo, Tokyo, Japan

${ }^{3}$ LGGE, CNRS, Grenoble, France

${ }^{4}$ Institute for Atmospheric and Climate Science, ETH Zurich, Zurich, Switzerland

${ }^{5}$ Climate Research Division, Environment and Climate Change, Toronto, Canada

${ }^{6}$ CNRM, Centre National de Recherches Météorologiques, Météo-France, Toulouse, France

${ }^{7}$ LMD-IPSL, Centre National de la Recherche Scientifique, Université Pierre et Marie-Curie, Ecole Normale Supérieure,

Ecole Polytechnique, Paris, France

${ }^{8}$ LSCE-IPSL: CEA-CNRS-UVSQ, Gif-sur-Yvette, France

${ }^{9}$ NASA Goddard Institute for Space Studies and Center for Climate Systems Research, Columbia University, New York, USA

${ }^{10}$ International Institute for Applied Systems Analysis, Laxenburg, Austria

${ }^{11}$ Laboratory for Climate Studies, National Climate Center, China Meteorological Administration, Beijing, China

${ }^{12}$ State Key Laboratory of Numerical Modeling for Atmospheric Sciences and Geophysical Fluid Dynamics, Institute of Atmospheric Physics, Chinese Academy of Sciences, Beijing, China

${ }^{13}$ Agenzia Nazionale per le nuove Tecnologie, l'energia e lo sviluppo economico sostenibile, Rome, Italy

${ }^{14}$ Climate and Global Dynamics Laboratory, National Center for Atmospheric Research, Boulder, USA

${ }^{15}$ Met Office (JCHMR) Maclean Building Crowmarsh Gifford Wallingford, Oxfordshire, UK

${ }^{16}$ Centre for Ecology and Hydrology, Maclean Building Crowmarsh Gifford Wallingford, Oxfordshire, UK

${ }^{17}$ Max-Planck-Institut für Meteorologie, Hamburg, Germany

${ }^{18}$ Environmental Sciences Division and Climate Change Science Institute, Oak Ridge National Laboratory, Oak Ridge, Tennessee, USA

${ }^{19}$ Department of Climate and Space Sciences and Engineering, University of Michigan, Ann Arbor, USA

${ }^{20}$ Euro-Mediterranean Center for Climate Change (CMCC), Climate Simulation and Prediction Division, Bologna, Italy

${ }^{21}$ CSIRO Oceans and Atmosphere, Aspendale, Australia

${ }^{22}$ Department of Civil and Environmental Engineering Princeton University, Princeton, USA

${ }^{23}$ Geography and Environment, University of Southampton, Southampton, UK

${ }^{24}$ Sorbonne Universités, UMR 7619 METIS, UPMC/CNRS/EPHE, Paris, France

Correspondence to: Bart van den Hurk (hurkvd@knmi.nl)

Received: 30 March 2016 - Published in Geosci. Model Dev. Discuss.: 11 April 2016

Revised: 27 July 2016 - Accepted: 28 July 2016 - Published: 24 August 2016 
Abstract. The Land Surface, Snow and Soil Moisture Model Intercomparison Project (LS3MIP) is designed to provide a comprehensive assessment of land surface, snow and soil moisture feedbacks on climate variability and climate change, and to diagnose systematic biases in the land modules of current Earth system models (ESMs). The solid and liquid water stored at the land surface has a large influence on the regional climate, its variability and predictability, including effects on the energy, water and carbon cycles. Notably, snow and soil moisture affect surface radiation and flux partitioning properties, moisture storage and land surface memory. They both strongly affect atmospheric conditions, in particular surface air temperature and precipitation, but also large-scale circulation patterns. However, models show divergent responses and representations of these feedbacks as well as systematic biases in the underlying processes. LS3MIP will provide the means to quantify the associated uncertainties and better constrain climate change projections, which is of particular interest for highly vulnerable regions (densely populated areas, agricultural regions, the Arctic, semi-arid and other sensitive terrestrial ecosystems).

The experiments are subdivided in two components, the first addressing systematic land biases in offline mode ("LMIP", building upon the 3rd phase of Global Soil Wetness Project; GSWP3) and the second addressing land feedbacks attributed to soil moisture and snow in an integrated framework ("LFMIP", building upon the GLACE-CMIP blueprint).

\section{Introduction}

Land surface processes, including heat fluxes, snow, soil moisture, vegetation, turbulent transfer and runoff, continue to be ranked highly on the list of the most relevant yet complex and poorly represented features in state-of-the-art climate models. People live on land, exploit its water and natural resources and experience day-to-day weather that is strongly affected by feedbacks with the land surface. The six Grand Challenges of the World Climate Research Program (WCRP) $)^{1}$ include topics governed primarily (Water Availability, Cryosphere) or largely (Climate Extremes) by land surface characteristics.

Despite the importance of a credible representation of land surface processes in Earth system models (ESMs), a number of systematic biases and uncertainties persist. Biases in hydrological characteristics (e.g., moisture storage in soil and snow, runoff, vegetation and surface water bodies), partitioning of energy and water fluxes (Seneviratne et al., 2010), definition of initial and boundary conditions at the appropriate spatial scale, feedback strengths (Koster et al., 2004; Qu and Hall, 2014) and inherent land surface related predictability

\footnotetext{
${ }^{1}$ http://www.wcrp-climate.org/grand-challenges
}

(Douville et al., 2007; Dirmeyer et al., 2013) are still subjects of considerable research effort.

These biases and uncertainties are problematic, because they affect, among others, forecast skill (Koster et al., 2010a), regional climate change patterns (Campoy et al., 2013; Seneviratne et al., 2013; Koven et al., 2012) and explicable trends in water resources (Lehning, 2013). In addition, there is evidence of the presence of large-scale systematic biases in some aspects of land hydrology in current climate models (Mueller and Seneviratne, 2014) and the terrestrial component of the carbon cycle (Anav et al., 2013; Mystakidis et al., 2016). Notably, land surface processes can be an important reason for a direct link between the climate models' temperature biases in the present period and in the future projections with increased radiative forcings at the regional scale (Cattiaux et al., 2013).

For snow cover, a better understanding of the links with climate is critical for interpretation of the observed dramatic reduction in springtime snow cover over recent decades (e.g., Derksen and Brown, 2012; Brutel-Vuilmet et al., 2013), to improve the seasonal to interannual forecast skill of temperature, runoff and soil moisture (e.g., Thomas et al., 2016; Peings et al., 2011) and to adequately represent polar warming amplification in the Arctic (e.g., Holland and Bitz, 2003). Snow-related biases in climate models may arise from the snow-albedo feedback (Qu and Hall, 2014; Thackeray et al., 2015), but also from the energy sink induced by snow melting in spring and the thermal insulation effect of snow on the underlying soil (Koven et al., 2012; Gouttevin et al., 2012). Temporal dynamics of snow-atmospheric coupling during various phases of snow depletion (Xu and Dirmeyer, 2011, 2012) are crucial for a proper representation of the timing and atmospheric response to snow melt. Phase 1 and 2 of the Snow Model Intercomparison Project (SnowMIP) (Etchevers et al., 2004; Essery et al., 2009) provided useful insights in the capacity of snow models of different complexity to simulate the snowpack evolution from local meteorological forcing but did not explore snow-climate interactions. Because of strong snow/atmosphere interactions, it remains difficult to distinguish and quantify the various potential causes for disagreement between observed and modeled snow trends and the related climate feedbacks.

Soil moisture plays a central role in the coupled landvegetation-snow-water-atmosphere system (Seneviratne et al., 2010; van den Hurk et al., 2011), where interactions are evident at many relevant timescales: diurnal cycles of land surface fluxes, seasonal and subseasonal predictability of droughts, floods and hot extremes, annual cycles governing the water buffer in dry seasons and shifts in the climatology in response to changing patterns of precipitation and evaporation. The representation of historical variations in land water availability and droughts still suffer from large uncertainties, due to model parameterizations, unrepresented hydrologic processes such as lateral groundwater flow, lateral flows connected to re-infiltration of river water or irrigation 
with river water, and/or atmospheric forcings (Sheffield et al., 2012; Zampieri et al., 2012; Trenberth et al., 2014; Greve et al., 2014; Clark et al., 2015). This also applies to the energy and carbon exchanges between the land and the atmosphere (e.g., Mueller and Seneviratne, 2014; Friedlingstein et al., 2013).

It is difficult to generate reliable observations of soil moisture and land surface fluxes that can be used as boundary conditions for modeling and predictability studies. Satellite retrievals, in situ observations, offline model experiments (Second Global Soil Wetness Project, GSWP2; Dirmeyer et al., 2006) and indirect estimates all have a potential to generate relevant information but are largely inconsistent, covering different model components, and suffer from methodological flaws (Mueller et al., 2013; Mao et al., 2015). As a consequence, the pioneering work on deriving soil moisture related land-atmosphere coupling strength (Koster et al., 2004) and regional/global climate responses in both present and future climate (Seneviratne et al., 2006, 2013) has been carried out using (ensembles of) modeling experiments. The second Global Land Atmosphere Coupling Experiment (GLACE2; Koster et al., 2010a) measured the actual temperature and precipitation skill improvement of using GSWP2 soil moisture initializations, which is much lower than suggested by the coupling strength diagnostics. Limited quality of the initial states, limited predictability and poor representation of essential processes determining the propagation of information through the hydrological cycle in the models all play a role.

Altogether, there are substantial challenges concerning both the representation of land surface processes in currentgeneration ESMs and the understanding of related climate feedbacks. The Land Surface, Snow and Soil moisture Model Intercomparison Project (LS3MIP) is designed to allow the climate modeling community to make substantial progress in addressing these challenges. It is part of the sixth phase of the Coupled Model Intercomparison Project (CMIP6; Eyring et al., 2016). The following section further develops the objectives and rationale of LS3MIP. The experimental design and analysis plan is presented thereafter. The final discussion section describes the expected outcome and impact of LS3MIP.

\section{Objectives and rationale}

The goal of the collection of LS3MIP experiments is to provide a comprehensive assessment of land surface, snow and soil moisture-climate feedbacks, and to diagnose systematic biases and process-level deficiencies in the land modules of current ESMs. While vegetation, carbon cycle, soil moisture, snow, surface energy balance and land-atmosphere interaction are all intimately coupled in the real world, LS3MIP focuses - necessarily - on the physical land surface in this complex system: interactions with vegetation and carbon cycle are included in the analyses wherever possible without losing this essential focus. In the complementary experiment Land Use MIP (LUMIP; see Lawrence et al., 2016) and C4MIP (Jones et al., 2016) vegetation, the terrestrial carbon cycle and land management are the central topics of analysis. LS3MIP and LUMIP share some model experiments and analyses (see below) to allow to be addressed the complex interactions at the land surface and yet remain able to focus on well-posed hypotheses and research approaches.

LS3MIP will provide the means to quantify the associated uncertainties and better constrain climate change projections, of particular interest for highly vulnerable regions (including densely populated regions, the Arctic, agricultural areas, and some terrestrial ecosystems).

The LS3MIP experiments collectively address the following objectives:

- evaluate the current state of land processes including surface fluxes, snow cover and soil moisture representation in CMIP DECK (Diagnostic, Evaluation and Characterization of Klima) experiments and CMIP6 historical simulations (Eyring et al., 2016), to identify the main systematic biases and their dependencies;

- estimate multi-model long-term terrestrial energy/water/carbon cycles, using the land modules of CMIP6 models under observation-constrained historical (land reanalysis) and projected future (impact assessment) climatic conditions considering land use/land cover changes;

- assess the role of snow and soil moisture feedbacks in the regional response to altered climate forcings, focusing on controls of climate extremes, water availability and high-latitude climate in historical and future scenario runs;

- assess the contribution of land surface processes to systematic Earth system model biases and the current and future predictability of regional temperature/precipitation patterns.

These objectives address each of the three CMIP6 overarching questions: (1) What are regional feedbacks and responses to climate change?; (2) What are the systematic biases in the current climate models?; and (3) What are the perspectives concerning the generation of predictions and scenarios?

LS3MIP encompasses a family of model experiments building on earlier multi-model experiments, particularly (a) offline land surface experiments (GSWP2 and its successor GSWP3), (b) the coordinated snow model intercomparisons SnowMIP phase 1 and 2 (Etchevers et al., 2004; Essery et al., 2009), and (c) the coupled climate timescale GLACEtype configuration (GLACE-CMIP, Seneviratne et al., 2013). Within LS3MIP the Land-only experimental suite is referred to as LMIP (Land Model Intercomparison Project) with the experiment ID Land, while the coupled suite is labeled as LFMIP (Land Feedback MIP). A detailed description of the 
model design is given below, and a graphical display of the various components within LS3MIP is shown in Fig. 1.

As illustrated in Fig. 2, LS3MIP is addressing multiple WCRP Grand Challenges and core projects. The LMIP experiment will provide better estimates of historical changes in snow and soil moisture at global scale, thus allowing the evaluation of changes in freshwater, agricultural drought and streamflow extremes over continents and a better understanding of the main drivers of these changes. The LFMIP experiments are of high relevance for the assessment of key feedbacks and systematic biases of land surface processes in coupled mode (Dirmeyer et al., 2015), and are particularly focusing on two of the main feedback loops over land: the snow-albedo-temperature feedback involved in Arctic Amplification, and the soil moisture-temperature feedback leading to major changes in temperature extremes (Douville et al., 2016). In addition, LS3MIP will allow the exchange of data and knowledge across the snow and soil moisture research communities that address a common physical topic: terrestrial water in liquid and solid form. Snow and soil moisture dynamics are often interrelated (e.g., Hall et al., 2008; $\mathrm{Xu}$ and Dirmeyer, 2012) and jointly contribute to hydrological variability (e.g., Koster et al., 2010b).

LS3MIP will also provide relevant insights for other research communities, such as global reconstructions of land variables that are not directly observed for detection and attribution studies (Douville et al., 2013), estimates of freshwater inputs to the oceans (which are relevant for sea-level changes and regional impacts; Carmack et al., 2015), the assessment of feedbacks shown to strongly modulate regional climate variability relevant for regional climate information, as well as the investigation of land climate feedbacks on large-scale circulation patterns and cloud occurrence (Zampieri and Lionello, 2011). This will thus also imply potential contributions to programmes like the Inter-Sectoral Impact Model Intercomparison Project (ISIMIP; Warszawski et al., 2014) and the International Detection and Attribution Group IDAG. LS3MIP is geared to extend and consolidate available data, models and theories to support human awareness and resilience to highly variable environmental conditions in a large ensemble of sectoral domains, including disaster risk reduction, food security, public safety, nature conservation and societal wellbeing.

Figure 3 illustrates the embedding of LS3MIP within CMIP6. LS3MIP fills a major gap by considering systematic land biases and land feedbacks. In this context, LS3MIP is part of a larger "LandMIP" series of CMIP6 experiments fully addressing biases, uncertainties, feedbacks and forcings from the land surface (Fig. 1), which are complementary to similar experiments for ocean or atmospheric processes (Seneviratne et al., 2014). In particular, we note that while LS3MIP focuses on systematic biases in land surface processes (Land) and on feedbacks from the land surface processes on the climate system (LFMIP), the complementary Land Use MIP (LUMIP) experiment addresses the role of
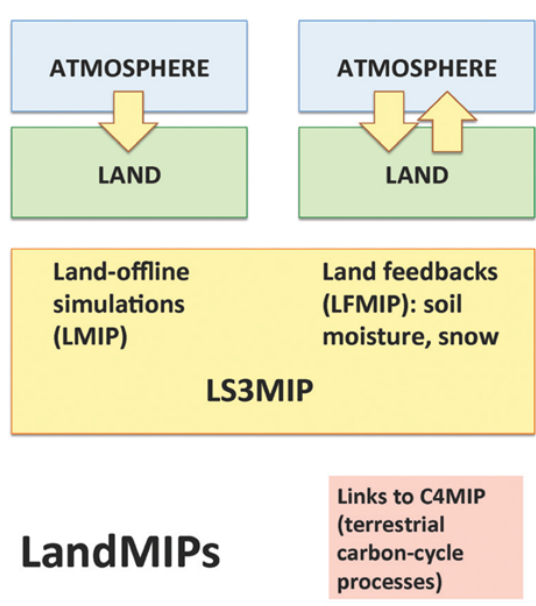

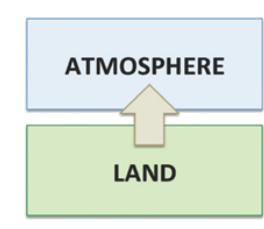

Land forcing: land use

LUMIP

Links to GeoMIP

(land albedo

testbed

experiment)
Figure 1. Structure of the "LandMIPs". LS3MIP includes (1) the offline representation of land processes (LMIP) and (2) the representation of land-atmosphere feedbacks related to snow and soil moisture (LFMIP). Forcing associated with land use is assessed in LUMIP. Substantial links also exist to C4MIP (terrestrial carbon cycle). Furthermore, a land albedo test bed experiment is planned within GeoMIP. From Seneviratne et al. (2014).

land use forcing on the climate system. The role of vegetation and carbon stores in the climate system is a point of convergence between LUMIP, C4MIP and LS3MIP, and the offline LMIP experiment will serve as land-only reference experiments for both the LS3MIP and LUMIP experiments. In addition, there will also be links to the C4MIP experiment with respect to impacts of snow and soil moisture processes (in particular droughts and floods) on terrestrial carbon exchanges and resulting feedbacks to the climate system.

\section{Experimental design}

The experimental design of LS3MIP consists of a series of offline land-only experiments (LMIP) driven by a land surface forcing data set and a variety of coupled model simulations (LFMIP) (see Fig. 4 and Table 1):

\subsection{Offline land model experiments ("Land offline MIP", experiment ID "Land")}

Offline simulations of land surface states and fluxes allow for the evaluation of trends and variability of snow, soil moisture and land surface fluxes, carbon stocks and vegetation dynamics, and climate change impacts. Within the CMIP6 program various Model Intercomparison Projects make use of offline terrestrial simulations to benchmark or force coupled climate model simulations: LUMIP focusing on the role of land use/land cover change, C4MIP to address the terrestrial component of the carbon cycle and its feedback to cli- 
LS3MIP within WCRP Core Projects and Grand Challenges

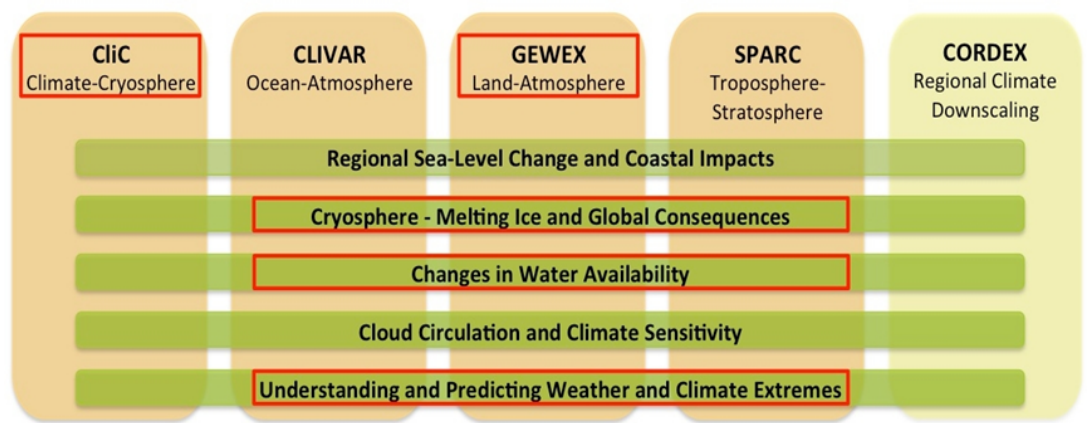

Figure 2. Relevance of LS3MIP for WCRP Core Projects and Grand Challenges ${ }^{2}$.

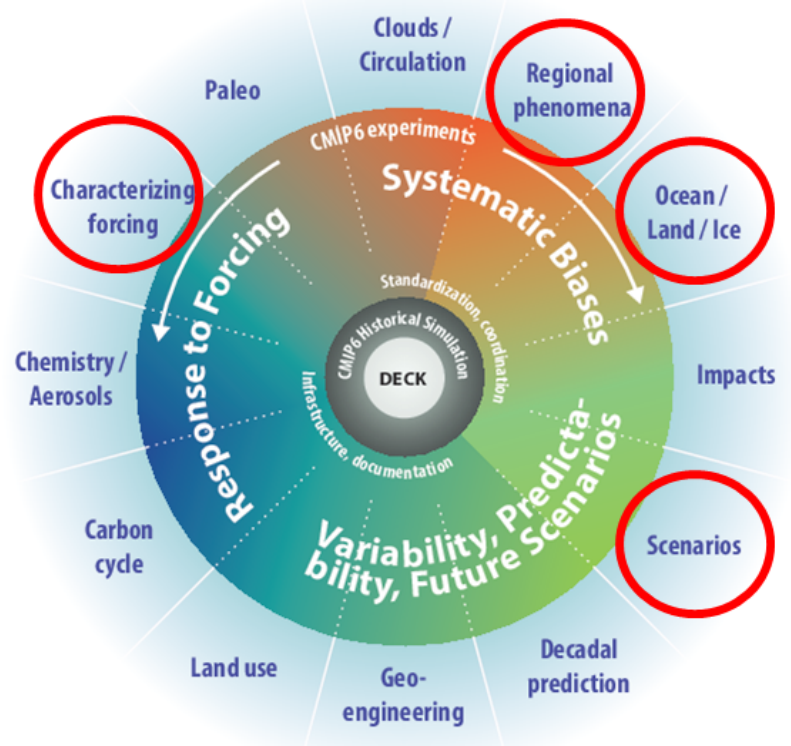

Figure 3. Embedding of LS3MIP within CMIP6. Adapted from Eyring et al. (2015).

mate, and LS3MIP to provide soil moisture and snow boundary conditions.

Meteorological forcings, ancillary data (e.g., land use/cover changes, surface parameters, $\mathrm{CO}_{2}$ concentration and nitrogen deposition) and documented protocols to spinup and execute the experiments are essential ingredients for a successful offline land model experiment (Wei et al., 2014). The first Global Soil Wetness Project (GSWP; Dirmeyer et al., 1999), covering two annual cycles (1987-1988), established a successful template, which was updated and fine-tuned in a number of follow-up experiments, both with

\footnotetext{
${ }^{2}$ http://wcrp-climate.org/index.php/grand-challenges; status December 2015
}

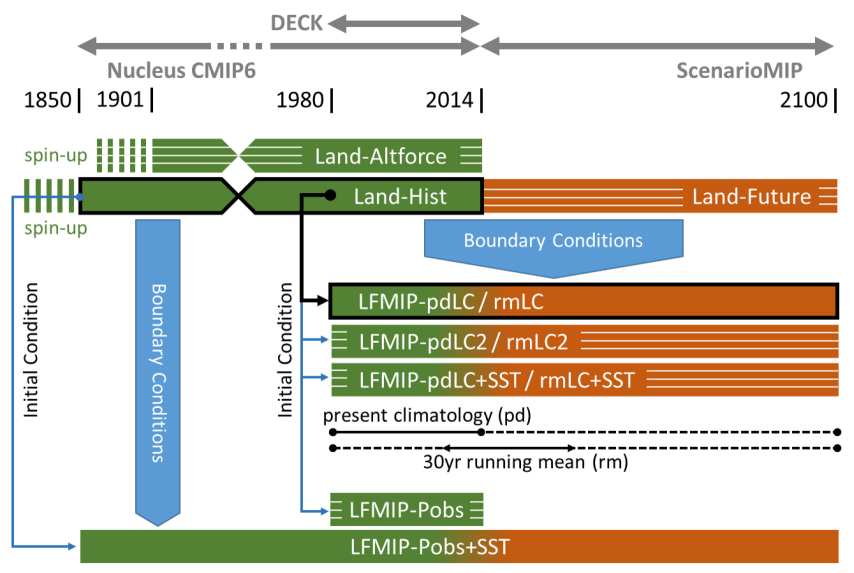

Figure 4. Schematic diagram for the experiment structure of LS3MIP. Tier 1 experiments are indicated with a heavy black outline, and complementary ensemble experiments are indicated with white hatched lines. Land-Altforce represents three alternative forcings for the Land-Hist experiment. For further details on the experiments and acronyms, see Table 1 and text.

global (Dirmeyer et al., 2006; Sheffield et al., 2006) and regional (Boone et al., 2009) coverage.

\subsubsection{Available data sets for meteorological forcing}

Offline experiments will primarily use GSWP3 ${ }^{3}$ (Tier 1) forcing (Kim et al., 2016) with alternate forcing used in Tier 2 experiments.

The third Global Soil Wetness Project (GSWP3) provides meteorological forcings for the entire 20th century and beyond, making extensive use of the 20th Century Reanalysis (20CR) (Compo et al., 2011). In this reanalysis product only surface pressure and monthly sea-surface temperature and sea-ice concentration are assimilated. The ensemble uncertainty in the synoptic variability of $20 \mathrm{CR}$ varies with the time-changing observation network. High correlations for

\footnotetext{
${ }^{3}$ http://hydro.iis.u-tokyo.ac.jp/GSWP3/
} 
Table 1. Summary of LS3MIP experiments. Experiments with specific treatment of subsets of land surface features are not listed in this overview.

\begin{tabular}{|c|c|c|c|c|c|c|c|c|}
\hline $\begin{array}{l}\text { Experiment ID and } \\
\text { tier }\end{array}$ & $\begin{array}{l}\text { Experiment } \\
\text { description/ } \\
\text { design }\end{array}$ & $\begin{array}{l}\text { Config } \\
(\mathrm{L} / \mathrm{A} / \mathrm{O})^{\mathrm{a}}\end{array}$ & Start & End & No. ens ${ }^{b}$ & $\begin{array}{l}\text { No. to- } \\
\text { tal } \\
\text { years }\end{array}$ & $\begin{array}{l}\text { Science question } \\
\text { and/or gap being } \\
\text { addressed }\end{array}$ & $\begin{array}{l}\text { Synergies with } \\
\text { other CMIP6 } \\
\text { MIPs }\end{array}$ \\
\hline Land-Hist (1) & $\begin{array}{l}\text { land only } \\
\text { simulations }\end{array}$ & $\mathrm{L}$ & 1850 & 2014 & 1 & 165 & $\begin{array}{l}\text { historical land } \\
\text { simulations }\end{array}$ & $\begin{array}{l}\text { LUMIP, C4MIP, } \\
\text { CMIP6 historical }\end{array}$ \\
\hline $\begin{array}{l}\text { Land-Hist-cruNcep } \\
\text { Land-Hist-princeton } \\
\text { Land-Hist-wfdei } \\
\text { (2) }\end{array}$ & $\begin{array}{l}\text { land only } \\
\text { simulations }\end{array}$ & $\mathrm{L}$ & 1901 & 2014 & 3 & 342 & $\begin{array}{l}\text { as Land-Hist but with } \\
\text { three different forcing } \\
\text { data sets (Princeton } \\
\text { forcing, CRU-NCEP, } \\
\text { and WFDEI) }\end{array}$ & \\
\hline Land-Future (2) & $\begin{array}{l}\text { land only } \\
\text { simulations }\end{array}$ & $\mathrm{L}$ & 2015 & 2100 & 6 & 516 & climate trend analysis & $\begin{array}{l}\text { LUMIP, C4MIP, } \\
\text { ScenarioMIP }\end{array}$ \\
\hline LFMIP-pdLC (1) & $\begin{array}{l}\text { prescribed land } \\
\text { conditions } 1980- \\
2014 \text { climate }\end{array}$ & LAO & 1980 & 2100 & 1 & 121 & $\begin{array}{l}\text { diagnose land-climate } \\
\text { feedback including } \\
\text { ocean response }\end{array}$ & ScenarioMIP \\
\hline LFMIP-pdLC2 (2) & $\begin{array}{l}\text { as LFMIP-pdLC } \\
\text { with multiple } \\
\text { model members }\end{array}$ & LAO & 1980 & 2100 & 4 & 484 & $\begin{array}{l}\text { diagnose land-climate } \\
\text { feedback including } \\
\text { ocean response }\end{array}$ & ScenarioMIP \\
\hline $\begin{array}{l}\text { LFMIP- } \\
\text { pdLC }+ \text { SST } \\
(2)\end{array}$ & $\begin{array}{l}\text { prescribed land } \\
\text { conditions 1980- } \\
2014 \text { climate; } \\
\text { SSTs prescribed }\end{array}$ & LA & 1980 & 2100 & 5 & 605 & $\begin{array}{l}\text { diagnose land-climate } \\
\text { feedback over land }\end{array}$ & ScenarioMIP \\
\hline $\begin{array}{l}\text { LFMIP-Pobs + SST } \\
\text { (2) }\end{array}$ & $\begin{array}{l}\text { land conditions } \\
\text { from Land-Hist; } \\
\text { SSTs prescribed }\end{array}$ & LA & 1901 & 2014 & 1 & 115 & $\begin{array}{l}\text { "perfect boundary } \\
\text { condition" simula- } \\
\text { tions }\end{array}$ & \\
\hline LFMIP-rmLC (1) & $\begin{array}{l}\text { prescribed } \\
\text { land conditions } \\
30 \text {-year running } \\
\text { mean }\end{array}$ & LAO & 1980 & 2100 & 1 & 121 & $\begin{array}{l}\text { diagnose land-climate } \\
\text { feedback including } \\
\text { ocean response }\end{array}$ & ScenarioMIP \\
\hline LFMIP-rmLC2 (2) & $\begin{array}{l}\text { as LFMIP-rmLC } \\
\text { with multiple } \\
\text { model members }\end{array}$ & LAO & 1980 & 2100 & 4 & 484 & $\begin{array}{l}\text { diagnose land-climate } \\
\text { feedback including } \\
\text { ocean response }\end{array}$ & ScenarioMIP \\
\hline $\begin{array}{l}\text { LFMIP-rmLC + SST } \\
\text { (2) }\end{array}$ & $\begin{array}{l}\text { prescribed } \\
\text { land conditions } \\
\text { 30-year running } \\
\text { mean; SSTs } \\
\text { prescribed }\end{array}$ & LA & 1980 & 2100 & 5 & 605 & $\begin{array}{l}\text { diagnose land-climate } \\
\text { feedback over land }\end{array}$ & ScenarioMIP \\
\hline LFMIP-Pobs (2) $)^{\text {ptbd }}$ & $\begin{array}{l}\text { initialized pseudo- } \\
\text { observations land }\end{array}$ & LAO & 1980 & 2014 & 10 & 350 & $\begin{array}{l}\text { land-related seasonal } \\
\text { predictability }\end{array}$ & CMIP6 historical \\
\hline
\end{tabular}

${ }^{\mathrm{a}}$ Config L/A/O refers to land/atmosphere/ocean model configurations. ${ }^{\mathrm{b}}$ No. ens refers to number of ensemble members. ${ }^{\mathrm{c}}$ No. total years is total number of simulation years. ${ }^{\text {ptbd }}$ experimental protocol needs to be detailed in a later stage.

geopotential height $(500 \mathrm{hPa})$ and air temperature $(850 \mathrm{hPa})$ with an independent long record (1905-2006) of upper-air data were found (Compo et al., 2011), comparable to forecast skill of a state-of-the-art forecasting system at 3 days lead time.

GSWP3 forcing data are generated based on a dynamical downscaling of 20CR. A simulation of the Global Spectral Model $(\mathrm{GSM})$, run at a T248 resolution $(\sim 50 \mathrm{~km})$ is nudged to the vertical structures of $20 \mathrm{CR}$ zonal and meridional winds and air temperature using a spectral nudging dy- namical downscaling technique that effectively retains synoptic features in the higher spatial resolution (Yoshimura and Kanamitsu, 2008). Additional bias corrections using observations, vertical damping (Hong and Chang, 2012) and single ensemble member correction (Yoshimura and Kanamitsu, 2013) are applied, giving considerable improvements.

Weedon et al. (2011) provide the meteorological forcing data for the EU Water and Global Change (WATCH) 
programme ${ }^{4}$, designed to evaluate global hydrological trends and impacts using offline modeling. The half-degree resolution, 3-hourly WATCH Forcing Data (WFD) was based on the ECMWF ERA-40 reanalysis and included elevation correction and monthly bias correction using CRU observations (and alternative GPCC precipitation total observations). WATCH hydrological modeling led to the WaterMIP study (Haddeland et al., 2011). The WFD stops in 2001, but within a follow-up project EMBRACE Weedon et al. (2014) generated the WFDEI data set that starts in 1979 and was recently extended to 2014. The WFDEI was based on the WATCH Forcing Data methodology but used the ERA-Interim reanalysis (4D-var and higher spatial resolution than ERA-40) so that there are offsets for some variable in the overlap period with the WFD. The forcing consists of 3-hourly ECMWF ERA-Interim reanalysis data (WFD used ERA-40) interpolated to half degree spatial resolution. The $2 \mathrm{~m}$ temperatures are bias-corrected in terms of monthly means and monthly average diurnal temperature range using CRU half degree observations. The $2 \mathrm{~m}$ temperature, surface pressure, specific humidity and downwards longwave radiation fluxes are sequentially elevation corrected. Shortwave radiation fluxes are corrected using CRU cloud cover observations and corrected for the effects of seasonal and interannual changes in aerosol loading. Rainfall and snowfall rates are corrected using CRU wet days per month and according to CRU or GPCC observed monthly precipitation gauge totals. The WFDEI data set is also used as forcing to the ISIMIP2.1 project, which focuses on historical validation of global water balance under transient land use change (Warszawski et al., 2014).

To support the Global Carbon Project ${ }^{5}$ (Le Quere et al., 2009) with annual updates of global carbon pools and fluxes, the offline modeling framework TRENDY ${ }^{6}$ applies an ensemble of terrestrial carbon allocation and land surface models. For this a forcing data set is prepared in which NCEP reanalysis data are bias corrected using the gridded in situ climate data from the Climate Research Unit (CRU), the socalled CRU-NCEP data set (Viovy and Ciais, 2009). This data set is currently available from 1901 to 2014 at $0.5^{\circ}$ horizontal spatial resolution and 6-hourly time step. It is being updated annually.

The Princeton Global Forcing data $\operatorname{set}^{7}$ (Sheffield et al., 2006) was developed as a forcing for land surface and other terrestrial models, and for analyzing changes in near-surface climate. The data set is based on 6-hourly surface climate from the NCEP-NCAR reanalysis, which is corrected for biases at diurnal, daily and monthly timescales using a variety of observational data sets. The data are available at 1.0, 0.5 and $0.25^{\circ}$ resolution and 3-hourly time step. The latest version (V2.2) covers 1901-2014, with a real-time extension

\footnotetext{
${ }^{4}$ http://www.eu-watch.org/

${ }^{5}$ http://www.globalcarbonproject.org/about/index.htm

${ }^{6}$ http://dgvm.ceh.ac.uk/node/21

${ }^{7}$ http://hydrology.princeton.edu/data.php
}

based on satellite precipitation and weather model analysis fields. The reanalysis precipitation is corrected by adjusting the number of rain days and monthly accumulations to match observations from CRU and the Global Precipitation Climatology Project (GPCP). Precipitation is downscaled in space using statistical relationships based on GPCP and the TRMM Multi-satellite Precipitation Analysis (TMPA), and to 3-hourly resolution based on TMPA. Temperature, humidity, pressure and longwave radiation are downscaled in space with account for elevation. Daily mean temperature and diurnal temperature range are adjusted to match the CRU monthly data. Shortwave and longwave surface radiation are adjusted to match satellite-based observations from the University of Maryland (Zhang et al., 2016) and to be consistent with CRU cloud cover observations outside of the satellite period. An experimental version (V3) assimilates station observations into the background gridded field to provide local-scale corrections (J. Sheffield, personal communication, February 2016).

Figure 5 shows the performance in terms of correlation and standard deviation of the forcing data sets compared to daily observations from 20 globally distributed in situ FLUXNET sites (Baldocchi et al., 2001). Although for precipitation intrinsic heterogeneity leads to significant differences with the in situ observations, longwave and shortwave downward radiation (not shown) and air temperature show variability characteristics similar to the observations.

The participating modeling groups are invited to run a number of experiments in this land-only branch of LS3MIP.

\subsubsection{Historical offline simulations: Land-Hist}

The Tier 1 experiments of the offline LMIP experiment consist of simulations using the GSWP3 forcing data for a historical (1831-2014) interval. The land model configuration should be identical to that used in the DECK and CMIP6 historical simulations for the parent coupled model.

The atmospheric forcing will be prepared at a standard $0.5 \times 0.5^{\circ}$ spatial resolution at 3-hourly intervals and distributed with a package to regrid data to the native grids of the global climate models (GCMs). Also vegetation, soil, topography and land/sea mask data will be prescribed following the protocol used for the CMIP6 DECK simulations. Spinup of the land-only simulations should follow the TRENDY protocol $^{8}$ which calls for recycling of the climate mean and variability from two decades of the forcing data set (e.g., 1831-1850 for GSWP3, 1901-1920 for the alternative land surface forcings). Land use should be held constant at 1850 as in the DECK 1850 coupled control simulation (piControl). See discussion and definition of "constant land-use" in Sect. 2.1 of LUMIP protocol paper (Lawrence et al., 2016). $\mathrm{CO}_{2}$ and all other forcings should be held constant at 1850 levels during spinup. For the period 1850 to the first year of

\footnotetext{
${ }^{8}$ http://dgvm.ceh.ac.uk/node/9
} 

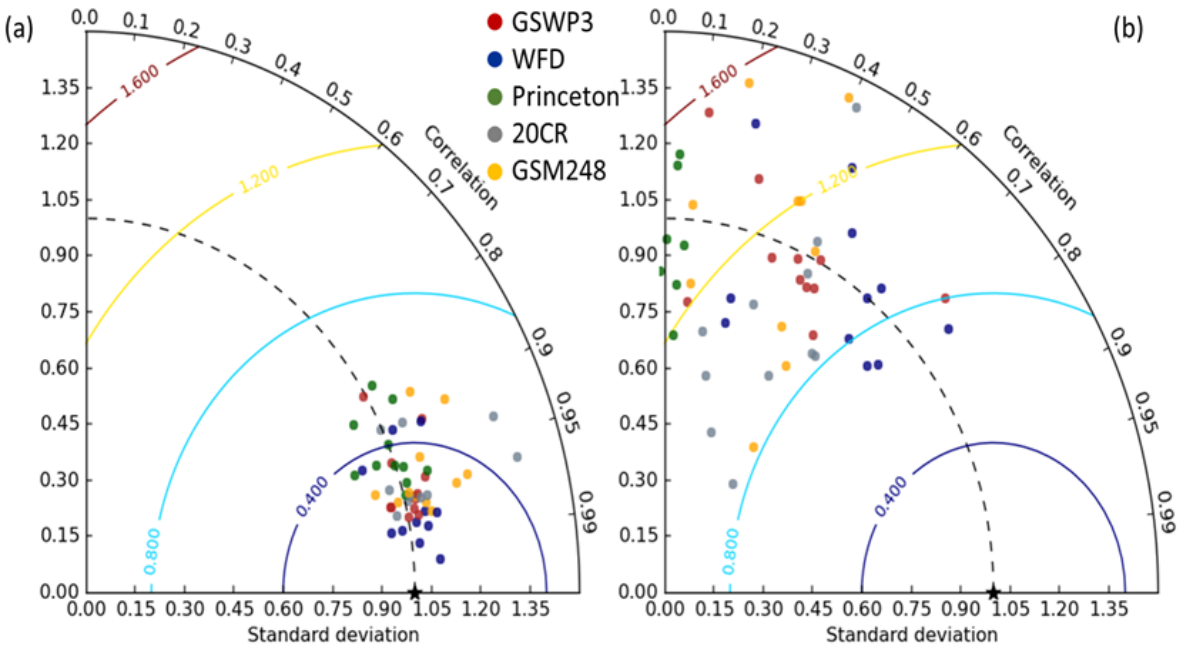

Figure 5. Taylor diagram for evaluating the forcing data sets comparing to daily observations from FLUXNET sites, as used by (Best et al., 2015): (a) $2 \mathrm{~m}$ air temperature and (b) precipitation. Red, blue and green dots indicate GSWP3, Watch Forcing Data (Weedon et al., 2011) and Princeton forcing (Sheffield et al., 2006), respectively. Grey and orange dots indicate 20CR and its dynamically downscaled product (GSM248).

the forcing data set, the forcing data should continue to be recycled but all other forcings (land-use, $\mathrm{CO}_{2}$, etc.) should be as in the CMIP6 historical simulation. Transient land use is a prescribed CMIP6 forcing and is described in the LUMIP protocol (Lawrence et al., 2016).

Interactions with the ocean MIP (OMIP; Griffies et al., 2016) are arranged by the use of terrestrial freshwater fluxes produced in the LMIP simulations as a boundary condition for the forced ocean-only simulations in OMIP, in addition to the forcing provided by (Dai and Trenberth 2002).

Single site time series of in situ observational forcing variables from selected reference locations (from FLUXNET, Baldocchi et al., 2001) are supplied in addition to the forcing data for additional site level validation. This allows the evaluation of land surface models in current GCMs such as applied by Best et al. (2015) and in ESM-SnowMIP (Earth System Model - Snow Module Intercomparison Project; see below). For snow evaluation, an international network of wellinstrumented sites has been identified, covering the major climate classes of seasonal snow, each of which poses unique challenges for the parameterization of snow related processes (see analysis strategy below).

Although Land-Hist is not a formal component of the DECK simulations which form the core of CMIP6 (see Fig. 3), the WCRP Working Group on Climate Modeling (WGCM) recognized the importance of these land-only experiments for the process of model development and benchmarking. A future implementation of a full or subset of this historical run is proposed to become part of the DECK in future CMIP exercises and is included as a Tier 1 experiment in LS3MIP. Land surface model output from this subset of
LMIP will also be used as boundary condition in some of the coupled climate model simulations, described below.

\subsubsection{Historical simulations with alternative forcings}

Additional Tier 2 experiments are solicited where the experimental setup is similar to the Tier 1 simulations, but using 3 alternative meteorological forcing data sets that differ from GSWP3: the Princeton forcing (Sheffield et al., 2006), WFD and WFDEI combined (allowing for offsets as needed; Weedon et al., 2014) and the CRU-NCEP forcing (Wei et al., 2014) used in TRENDY (Sitch et al., 2015). These Tier 2 experiments cover the period 1901-2014. The model outputs will allow assessment of the sensitivity of land-only simulations to uncertainties in forcing data. Differences in the outputs compared to the primary runs with the GSWP3 forcing will help in understanding simulation sensitivity to the selection of forcing data sets. Kim (2010) utilized a similarity index ( $\Omega$; Koster et al., 2000) to estimate the uncertainty derived from an ensemble of precipitation observation data sets relative to the uncertainty from an ensemble of model simulations for evapotranspiration and runoff. The joint utilization of common monthly observations by the various forcing data sets leads to a high value of $\Omega$ when evaluated using monthly mean values. However, evaluation of data set consistency of monthly variance leads to much larger disparities and considerably lower values of $\Omega$ (Fig. 6). This uncertainty will propagate differently to other hydrological variables, such as runoff or evapotranspiration (Kim, 2010). 

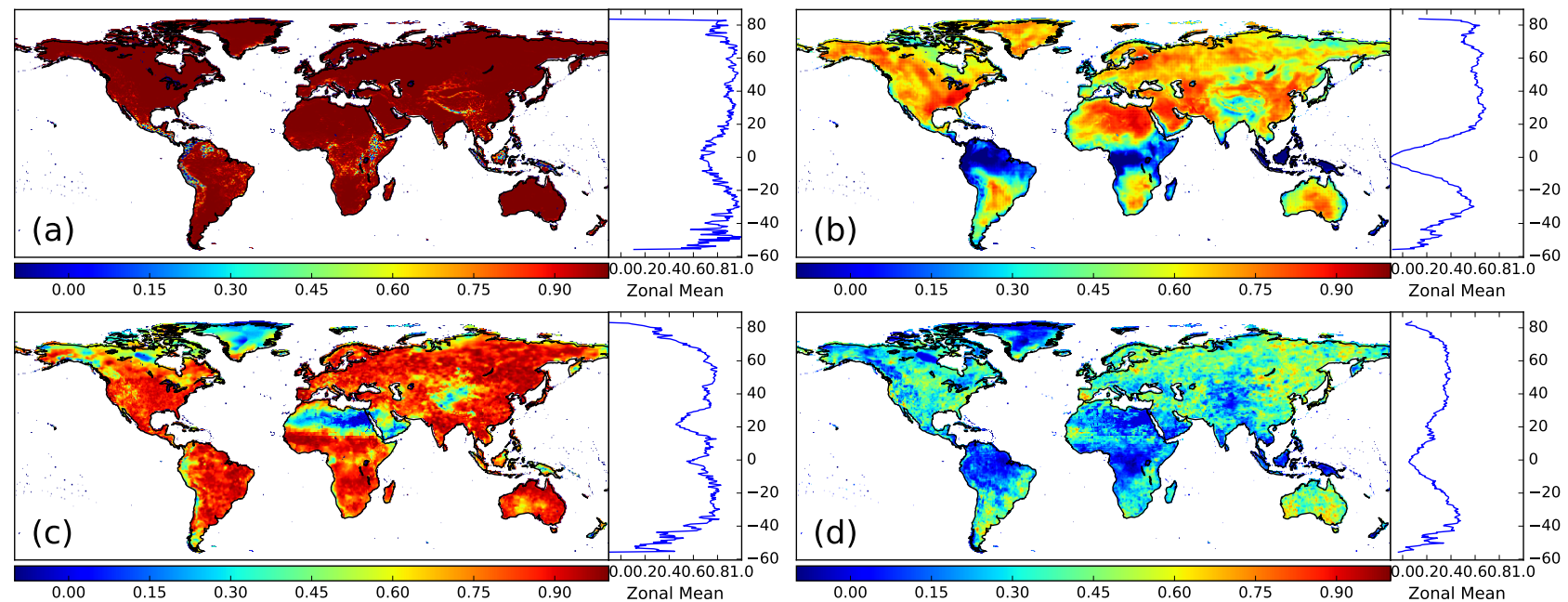

Figure 6. Global distributions of the similarity index $(\Omega)$ for 2001-2010 of monthly mean (a, c) and (b, d) monthly variance (calculated from daily data from each data set) of $2 \mathrm{~m}$ air temperature (top panels) and precipitation (bottom panels), respectively. Shown are global distributions and zonal means. After Kim (2010).

\subsubsection{Climate change impact assessment: Land-Future}

A set of future land-only time slice simulations (2015-2100) will be generated via forcing data obtained from at least $2 \mathrm{fu}$ ture climate scenarios from the ScenarioMIP (O'Neill et al., 2016) and will be executed at a later stage during CMIP6. Tentatively, Shared Socioeconomic Pathway SSP5-8.5 and SSP4-3. $7^{9}$ will be selected, run by 3 model realizations each. The models will be chosen based on the evaluation of the results from the Historical simulations from the CMIP6 Nucleus in order to represent the ensemble spread efficiently and reliably (Evans et al., 2013). To generate a set of ensemble forcing data for the future, a trend preserving statistical bias correction method will be applied to the 3-hourly surface meteorology variables (Table A4) from the scenario output (Hempel et al., 2013; Watanabe et al., 2014). Gridded forcings will be provided in a similar data format as the historical simulations.

Land-Future is a Tier 2 experiment in LS3MIP and focuses on assessment of climate change impact (e.g., shifts of the occurrence of critical water availability due to changing statistical distributions of extreme events) and on the assessment of the land surface analogue of climate sensitivity for various key land variables (Perket et al., 2014; Flanner et al., 2011).

\subsection{Prescribed land surface states in coupled models for land surface feedback assessment ("Land Feedback MIP", LFMIP)}

Land surface processes do not act in isolation in the climate system. A tight coupling with the overlying atmosphere takes place on multiple temporal and spatial scales. A systematic assessment of the strength and spatial structure of land surface interaction at subcontinental, seasonal timescales has been performed with the initial GLACE setup (GLACE1 and GLACE2 experiments; Koster et al., 2004) in which essentially the spread in an ensemble simulation of a coupled land-atmosphere model was compared to a model configuration in which the land-atmosphere interaction was greatly bypassed by prescribing soil conditions throughout the simulation in all members of the ensemble. Examination of the significance of land-atmosphere feedbacks at the centennial climate timescale was later explored at the regional scale in a single-model study (Seneviratne et al., 2006) and on global scale in the GLACE-CMIP5 experiment in a small model ensemble (Seneviratne et al., 2013).

A protocol very similar to the design of GLACE-CMIP5 is followed in LFMIP. Parallel to a set of reference simulations taken from the CMIP6 DECK, a set of forced experiments is carried out where land surface states are prescribed from or nudged towards predescribed fields derived from coupled simulations. The land surface states are prescribed or nudged at a daily timescale. This setup is similar to the Flux Anomaly Forced MIP (FAFMIP, Gregory et al., 2016), where the role of ocean-atmosphere interaction at climate timescales is diagnosed by idealized surface perturbation experiments.

While earlier experiments used model configurations with prescribed SST and sea ice conditions, the Tier 1 experiment in LFMIP will be based on coupled atmosphere-ocean global climate model (AOGCM) simulations and comprise simulations for a historical (1980-2014) and future (2015-2100) time range. The selection of the future scenario (from the ScenarioMIP experiment) will be based on the choices made in the offline LMIP experiment (see above).

\footnotetext{
${ }^{9}$ https://cmip.ucar.edu/scenario-mip/experimental-protocols
} 
In GLACE-CMIP5 only soil moisture states were prescribed in the forced experiments. The configuration of the particular land surface models may introduce the need to make different selections of land surface states to be prescribed, for instance to avoid strong inconsistencies in the case of frozen ground (soil moisture rather than soil water state should be prescribed; M. Hauser, ETH Zurich, personal communication, 2015), melting snow or growing vegetation. Prescribing surface soil moisture only (experiment "S" in Koster et al., 2006) gave unrealistic values of the surface Bowen ratio. A standardization of this selection is difficult as the implementation and consequences may be highly model specific. Here we recommend to prescribe only the water reservoirs (soil moisture, snow mass). The disparity of possible implementations is adding to the uncertainty range generated by the model ensemble, similar to the degree to which implementation of land use, flux corrections or downscaling adds to this uncertainty range. Participating modeling groups are encouraged to apply various test simulations focusing both on technical feasibility and experimental impact to evaluate different procedures to prescribe land surface conditions.

The earlier experience with GLACE-type experiments has revealed a number of technical and scientific issues. Because in most GCMs the land surface module is an integral part of the code describing the atmosphere, prescribing land surface dynamics requires a non-conventional technical interface, reading and replacing variables throughout the entire simulations. Many LS3MIP participants have participated earlier in GLACE-type experiments, but for some the code adjustments will require a technical effort. Interpretation of the effect of the variety of implementations of prescribed land surface variables by the different modeling groups (see above) is helped by a careful documentation of the way the modeling groups have implemented this interface. Tight coordination and frequent exchange among the participating modeling groups on the technical modalities of the implementation of the required forcing methods will be ensured during the preparatory phase of LS3MIP in order to maximize the coherence of the modeling exercise and to facilitate the interpretation of the results.

By design, the prescribed land surface experiments do not fully conserve water and energy, similar to the setup of the Atmospheric Model Intercomparison Project (AMIP), nudged and data assimilation experiments. A systematic addition or removal of water or energy can even emerge as a result of asymmetric land surface responses to dry and to wet conditions, e.g., when surface evaporation or runoff depend strongly non-linearly to soil moisture or snow states (e.g., Jaeger and Seneviratne, 2011). Also, unrepresented processes (such as water extraction for irrigation or exchange with the groundwater) may lead to imbalances in the budget (Wada et al., 2012). This systematic alteration of the water and energy balance may not only perturb the simulation of present-day climate (e.g., Douville, 2003; Douville et al.,
2016) but may also interact with the projected climate change signal, where altered climatological soil conditions can contribute to the climate change induced temperature or precipitation signal or water imbalances can lead to imposed runoff changes that could affect ocean circulation and SSTs. Earlier GLACE-type experiments revealed that the problems of water conversion are often reduced when prescribed soil water conditions are taken as the median rather than the mean of a sample over which a climatological mean is calculated (Hauser et al., 2016). In the analyses of the experiments this asymmetry and lack of energy/water balance closure will be examined and put in context of the climatological energy and water balance and its climatic trends.

To be able to best quantify the forcing that prescribing the land surface state represents, the increments of both snow and soil moisture imposed as a consequence of this prescription are required as an additional output. This will enable us to estimate the amplitude of implicit water and energy fluxes imposed by the forcing procedure.

Complementary experiments following an almost identical setup as LFMIP, but limiting the prescription of land surface variables to snow-related variables and thus leaving soil moisture free-running, are carried out in the framework of the ESM-SnowMIP carried out within the WCRP Grand Challenge "Melting Ice and Global Consequences"10. ESMSnowMIP being tightly linked to LS3MIP, these complementary experiments will allow separating effects of soil moisture and snow feedbacks.

\subsubsection{Tier 1 experiments in LFMIP}

Similar to the setup of GLACE-CMIP5 (Seneviratne et al., 2013), the core experiments of LFMIP (tier 1) evaluate two different sets of prescribed land surface conditions (snow and soil moisture):

- LFMIP-pdLC: the experiments comprise transient coupled atmosphere-ocean simulations in which a selection of land surface characteristics is prescribed rather than interactively calculated in the model. This "climatological" land surface forcing is calculated as the mean annual cycle in the period 1980-2014 from the historical GCM simulations. The experiment aims at diagnosing the role of land-atmosphere feedback at the climate timescale. Seneviratne et al. (2013) found a substantial effect of changes in climatological soil moisture on projected temperature change in a future climate, both for seasonal mean and daytime extreme temperature in summer. Effects on precipitation are less clear, and the multi-model nature of LS3MIP is designed to sharpen these quantitative effects. Also, LS3MIP will take a potential damping (or amplifying) effect of oceanic responses on altered land surface conditions into account,

\footnotetext{
${ }^{10} \mathrm{http} / / / \mathrm{www} . c l i m a t e-c r y o s p h e r e . o r g / a c t i v i t i e s / t a r g e t e d /$ esm-snowmip
} 
in contrast to GLACE-CMIP5. Experiments using this setup (i.e., coupled ocean) in a single-model study have shown that the results could be slightly affected by the inclusion of an interactive ocean, although the effects were not found to be large overall (Orth and Seneviratne, 2016).

- LFMIP-rmLC: a prescribed climatology using a transient 30-yr running mean, where a comparison to the standard CMIP6 runs allows diagnosis of shifts in the regions of strong land-atmosphere coupling as recorded by e.g., Seneviratne et al. (2006), and shifts in potential predictability related to land surface states (Dirmeyer et al., 2013).

Both sets of simulations cover the historical period (18502014 ) and extend to 2100 , based on a forcing scenario to be identified at a later stage. The procedure to initialize the land surface states in the ensemble members is left to the participant, but should allow to generate sufficient spread that can be considered representative for the climate system under study Koster et al. (2006) proposed a preference hierarchy of methods depending on the availability of initialization fields, and LS3MIP will follow this proposal.

Output in high temporal resolution (daily, as well as subdaily for some fields and time slices) is required to address the role of land surface-climate feedbacks on climate extremes over land.

Multi-member experiments are encouraged, but the mandatory tier 1 simulations are limited to one realization for each of the two prescribed land surface time series described above.

\subsubsection{Tier 2 experiments in LFMIP}

To analyze a number of additional features of landatmosphere feedbacks, a collection of tier 2 simulations is proposed in LS3MIP.

- Simulations with observed SST - The AOGCM simulations from Tier 1 are duplicated with a prescribed SST configuration taken from the AMIP runs in the DECK atmospheric global climate model (AGCM), in order to isolate the role of the ocean in propagating and damping/reinforcing land surface responses on climate (Koster et al., 2000). Both the historic and running mean land surface simulations are requested (LFMIPpdLC + SST and -rmLC + SST, respectively).

- Simulations with observed SST and Land-Hist output - A "pseudo-observed boundary condition" set of experiments use the AMIP SSTs and the Land-Hist land boundary conditions generated by the land surface model used in the participating ESM, leading to simulations driven by surface fields that are strongly controlled by observed forcings. This will only cover the historic period (1901-2014) (LFMIP-PObs + SST). For this the land-only simulations in LMIP need to be interpolated to the native GCM grid, preserving land-sea boundaries and other characteristics.

- Separate effects of soil moisture and snow, and role of additional land parameters and variables - Additional experiments, in which only snow, snow albedo or soil moisture is prescribed will be conducted to assess the respective feedbacks in isolation, and have control on possible interactions between snow cover and soil moisture content. Also vegetation parameters and variables (e.g., leaf area index, canopy height and thickness) are considered. These experiments are not listed in Table 1 , but will be detailed in a follow-up protocol to be defined later.

- Fixed land use conditions - In conjunction with the Land Use MIP (LUMIP), a repetition of the Tier 1 experiment under fixed 1850 land cover and land use conditions highlights the role of soil moisture in modulating the climate response to land cover and land use (not listed in Table 1).

\subsection{Prescribed land surface states derived from pseudo-observations (LFMIP-Pobs)}

The use of LMIP (land-only simulations) to initialize the AOGCM experiments (LFMIP) allows a set of predictability experiments in line with the GLACE2 setup (Koster et al., 2010a). The LFMIP-Pobs experiment is an extension to GLACE2 by (a) allowing more models to participate, (b) improving the statistics by extending the original 1986-1995 record to 1980-2014, (c) evaluating the quality of newly available land surface forcings and (d) executing the experiments in AOGCM mode. Koster et al. (2010a) and van den Hurk et al. (2012) concluded that the forecast skill improvement from models using initial soil moisture conditions was relatively low. Possible causes for this low skill are the limited record length and limited quality of the (precipitation) observations used to generate the soil conditions. These issues are explicitly addressed in LFMIP-Pobs.

All LFMIP-Pobs experiments are Tier 2, which also gives room for additional model design elements such as the evaluation of various observational data sources (such as for snow mass (Snow Water Equivalent; SWE) or snow albedo, using satellites derived, reanalysis and land surface model outputs). The predictability assessments include the evaluation of the contribution of snow cover melting and its related feedbacks to the underestimation of recent boreal polar warming by climate models.

The experimental protocol (number of simulations years, ensemble size, initialization, model configuration, output diagnostics) has a strong impact on the results of the experiment (e.g., Guo and Dirmeyer, 2013). This careful design of the LFMIP-Pobs experiment needed for a successful implementation has currently not yet taken place. Therefore these 
experiments are listed as Tier 2 in Table 1, with the comment that the detailed experimental protocol still needs to be defined.

\section{Analysis strategy}

LS3MIP is designed to push the land surface component of climate models, observational data sets and projections to a higher level of maturity. Understanding the propagation of model and forecast errors and the design of model parameterizations is essential to realize this goal. The LS3MIP steering group is a multi-disciplinary team (climate modelers, snow and soil moisture model specialists, experts in local and remotely sensed data of soil moisture and snow properties) that ensures that the experiment setups, model evaluations and analyses/interpretations of the results are pertinent.

For both snow and soil moisture the starting point will be a careful analysis of model results from on the one hand (a) the DECK historic simulations (both the AMIP and the historical coupled simulation) and (b) on the other hand the (offline) LMIP historical simulations.

For the evaluation of snow representation in the models, large-scale high-quality data sets of snow mass (SWE) and snow cover extent (SCE) with quantitative uncertainty characteristics will be provided by the Satellite Snow Product Intercomparison and Evaluation Experiment (SnowPEX ${ }^{11}$ ). Analysis within SnowPEX is providing the first evaluation of satellite derived snow extent (15 participating data sets) and SWE derived from satellite measurements, land surface assimilation systems, physical snow models and reanalyses (7 participating data sets). Internal consistency between products, and bias relative to independent reference data sets are being derived based on standardized and consistent protocols. The evaluation of variability and trends in terrestrial snow cover extent and mass was examined previously for CMIP3 and CMIP5 by e.g., Brown and Mote (2009), Derksen and Brown (2012) and Brutel-Vuilmet et al. (2013). While these assessments were based on single observational data sets, and hence provide no perspective on observational uncertainty and spread relative to multi-model ensembles, standardized multi-source data sets generated by SnowPEX will allow assessment using a multi-data-set observational ensemble (e.g., Mudryk et al., 2015). For snow albedo, multiple satellite-derived data sets are available, including 16day MODIS ${ }^{12}$ data from 2001-present, the ESA GlobAlbedo product $^{13}$, the recently updated twice-daily APP-x ${ }^{14}$ product (1982-2011), and a derivation of the snow shortwave radiative effect from 2001-2013 (Singh et al., 2015). Satellite retrievals of snow cover fraction in forested and mountainous areas is an ongoing area of uncertainty which influences the

\footnotetext{
${ }^{11} \mathrm{http} / / /$ calvalportal.ceos.org/projects/snowpex

${ }^{12} \mathrm{http}: / /$ modis-atmos.gsfc.nasa.gov/ALBEDO/

$13 \mathrm{http}: / / \mathrm{www}$.globalbedo.org

${ }^{14} \mathrm{http}: / /$ stratus.ssec.wisc.edu/products/appx/appx.html
}

essential diagnostics related to climate sensitivity of snow cover (Thackeray et al., 2015), feeding into essential diagnostics related to climate sensitivity of snow cover $(\mathrm{Qu}$ and Hall, 2014; Fletcher et al., 2012).

In the case of soil moisture, land hydrology and vegetation state, several observations-based data sets will be used in the evaluation of the coupled DECK simulations and offline Land experiments. Data considered will include the first multidecadal satellite-based global soil moisture record (Essential Climate Variable Soil Moisture ECVSM) (Liu et al., 2012; Dorigo et al., 2012), long-term (2002-2015) records of terrestrial water storage from the GRACE satellite (Rodell et al., 2009; Reager et al., 2016; Kim et al., 2009), the multi-product LandFlux-EVAL evapotranspiration synthesis (Mueller et al., 2013), multi-decadal satellite retrievals of the Fraction of Photosynthetically Absorbed Radiation (FPAR, e.g., Gobron et al., 2010; Zscheischler et al., 2015), and upscaled Fluxnet based products (Jung et al., 2010).

Several details of snow and soil moisture dynamical processes can be indirectly inferred through the analysis of river discharge (Orth et al., 2013; Zampieri et al., 2015). Variables simulated by the routing schemes included in the land surface models can be compared with the station data available from the Global Runoff Database (GRDC $\left.{ }^{15}\right)$. Combined use of in situ discharge observations and terrestrial water storage changes observed by GRACE will verify how the land surface simulations partition the terms in the water balance equation (i.e., precipitation, evapotranspiration, runoff and water storage changes)(Kim et al., 2009).

The coupled LS3MIP (LFMIP) simulations will be analyzed in concert with the control runs to quantify various climatic effects of snow and soil moisture, detect systematic biases and diagnose feedbacks. Anticipated analyses include the following.

- Drivers of variability at multiple timescales - Comparison of simulations with prescribed soil moisture and snow (LFMIP-pdLC) allows quantification of the impact of land surface state variability on variability of climate variables such as temperature, relative humidity, cloudiness, precipitation and river discharge at several timescales. The LFMIP-rmLC simulation allows evaluation of this contribution on seasonal timescales, and changes of patterns of high/low land surface impact in a future climate. In particular, a focus will be put on impacts on climate extremes (temperature extremes, heavy precipitation events, see e.g., Seneviratne et al., 2013) and the possible role of land-based feedbacks in amplifying regional climate responses compared to changes in global mean temperature (Seneviratne et al., 2016). A secondary focus will be on the impacts of snow and soil moisture variability on the extremes of river discharge, which can be related to large-scale floods and to nonlocal propagation of drought signals. These aspects will

\footnotetext{
${ }^{15}$ http://www.bafg.de/GRDC
} 
be analyzed in the context of water management and to quantify feedbacks of river discharge to the climate system (through the discharge in the oceans, Materia et al., 2012; Carmack et al., 2015) and to the carbon cycle (through the methane produced in flooded areas, Meng et al., 2015).

- Attribution of model disagreement - The multi-model set up of the experiment allows closer inspection of the effects of modeled soil moisture and snow (and related processes such as plant transpiration, photosynthesis, or snowmelt) on calculated land temperature, precipitation, runoff, vegetation state, and gross primary production. The comparison of LFMIP-pdLC and LFMIPrmLC will be useful to isolate model disagreement in land surface feedbacks potentially induced by including coupling to a dynamic ocean despite similar land response to climate change.

- Emergent constraints - While the annual cycle of snow cover and local temperature (Qu and Hall, 2014), and the relation between global mean temperature fluctuations and $\mathrm{CO}_{2}$-concentration (Cox et al., 2013) provide observational constraints on snow-albedo and carbonclimate feedback, respectively, similar emergent constraints may be defined to constrain (regional) soil moisture or snow related feedbacks with temperature or hydrological processes such as, for instance, the timing of spring onset which may be related to snowmelt, spring river discharge (Zampieri et al., 2015) and vegetation phenology (Xu et al., 2013). Use of appropriate observations and diagnostics as emergent constraints will reduce uncertainties in projections of mean climate and extremes (heat extremes, droughts, floods) (Hoffman et al., 2014). The analysis of amplitude and timing of seasonality of hydrological and ecosystem processes will provide additional diagnostics.

- Attribution of model bias - A positive relationship between model temperature bias in the current climate, and (regional) climate response can partly be attributed to the soil moisture-climate feedback, which acts on both the seasonal and climate timescale (Cheruy et al., 2014). A multi-model assessment of this relationship is enabled via LS3MIP. The comparison of AMIP-DECK, LFMIP-CA and LFMIP-LCA will be used to assess the impact of atmospheric-related errors in land boundary conditions on the AGCM biases.

- Changes in feedback hotspots and predictability patterns - Land surface conditions don't exert uniform influence on the atmosphere in all areas of the globe: a distribution of strong interaction "hotspots" and areas of high potential predictability contributions from the land surface exists (e.g., Koster et al., 2004). These patterns may change in a future climate (e.g., Seneviratne et al., 2006). A multi-model assessment such as the one foreseen in LS3MIP allows mapping changes in these patterns, with implications for the occurrence of droughts, heat waves, irrigation limitations or river discharge anomalies and their predictability (Dirmeyer et al., 2013).

- Snow shortwave radiative effect analysis - The snow shortwave radiative effect (SSRE) can be diagnosed through parallel calculations of surface albedo and shortwave fluxes with and without model snow on the ground or in the vegetation canopy (Perket et al., 2014). This metric provides a precise, overarching measure of the snow-induced perturbation to solar absorption in each model, integrating over the variable influences of vegetation masking, snow grain size, snow cover fraction, soot content, etc. SSRE is analogous to the widely used cloud radiative effect diagnostic, and its time evolution provides a measure of snow albedo feedback in the context of changing climate (Flanner et al., 2011). We recommend that the diagnostic snow shortwave radiative effect (SSRE) calculation be implemented in standard LS3MIP simulations (Tiers 1 and 2). This will enable us to evaluate the integrated effect of model snow cover on surface radiative fluxes.

- Complementary snow-related offline experiments - Additional offline experiments are enabled by the provision of a collection of localized forcing data in the Land-Hist experiment (see above). For snow, a network of well-equipped sites is analyzed in detail for characteristic features (for example, snow-vegetation interactions for taiga snow; wind-driven processes for tundra snow; snow-rain partitioning for maritime snow). Reference simulations at these sites, consistent with previous SnowMIP experiments (Essery et al., 2009), will be complemented by additional experiments with (1) a fixed snow albedo; and (2) the insulative properties of snow removed in order to isolate the contributions of snow to the surface energy budget and ground thermal regime. This will be implemented within the ESMSnowMIP ${ }^{16}$ initiative, aimed at improving our understanding of sources of coupled model biases (global offline and site scale experiments) in order to identify priority avenues for future model development.

Regarding the snow analyses, the initial geographical focus of LS3MIP is on the continental snow cover of both hemispheres, both in ice-free areas (Northern Eurasia and North America) and on the large ice sheets (Greenland and Antarctica). Effects of snow on sea ice and the quality of the representation of snow on sea ice in climate models will be explored later, but they are of interest because of strong recent trends of Arctic sea ice decline and the potential amplifying effect of earlier spring snow melt over land.

\footnotetext{
${ }^{16} \mathrm{http} / / / \mathrm{www} . c l i m a t e-c r y o s p h e r e . o r g / a c t i v i t i e s / t a r g e t e d /$ esm-snowmip
} 
Table 2. Earth system modeling groups participating in LS3MIP.

\begin{tabular}{lll}
\hline Model name & Institute & Country \\
\hline ACCESS & CSIRO/Bureau of Meteorology & Australia \\
ACME Land Model & U.S. Department of Energy & USA \\
BCC-CSM2-MR & BCC, CMA & China \\
CanESM & CCCma & Canada \\
CESM & & USA \\
CMCC-CM2 & Centro Euro-Mediterraneo sui Cambiamenti Climatici & Italy \\
CNRM-CM & CNRM-CERFACS & France \\
EC-Earth & SMHI and 26 other institutes & Sweden and 9 other \\
& & European countries \\
FGOALS & LASG, IAP, CAS & China \\
GISS & NASA GISS & USA \\
IPSL-CM6 & IPSL & France \\
MIROC6-CGCM & AORI, University of Tokyo/JAMSTEC/National & Japan \\
& Institute for Environmental Studies & \\
MPI-ESM & Max Planck Institute for Meteorology (MPI-M) & Germany \\
MRI-ESM1.x & Meteorological Research Institute & Japan \\
NorESM & Norwegian Climate Service Centre & Norway \\
hadGEM3 & Met Office & UK \\
\hline
\end{tabular}

For soil moisture, the geographical focus is on all land areas, with special interest in agricultural locations with strong land-atmosphere interaction (transition zones between wet and dry climates), extensive irrigation areas, and high interannual variability of warm season climate in densely populated areas.

The analyses are carried out on a standardized model output data set. A summary of the requested output data is given in tables in the Appendix.

\section{Time line, participating models and interaction strategy}

The offline land surface experiments (Land-Hist) are expected to be completed in early 2017. Future time slices can only be performed when the Scenario-MIP results become available. All coupled LS3MIP simulations and their subsequent analyses will be timed after the completion of the DECK and historical 20th century simulations, expected by mid-2017. Table 2 lists the participating Earth system modeling groups.

The organizational structure of LS3MIP relies on active participation of modeling groups. Coordination structures are in place for the collection and dissemination of data and model results (Eyring et al., 2016), and for the organization of meetings and seminars (by the core team members of LS3MIP, first six authors of this manuscript). Different from earlier experiments such as GSWP2 and GLACE1/2, no central "analysis group" is put in place that is responsible for the analyses as proposed in this manuscript. The execution and publication of analyses is considered to be a community ef- fort of participating researchers, in order to avoid duplication of efforts and coordinate the production of scientific papers.

\section{Discussion: expected outcome and impact of LS3MIP}

The treatment of the land surface in the current generation of climate models plays a critical role in the assessment of potential effects of widespread changes in radiative forcing, land use and biogeochemical cycles. The land surface both "receives" climatic variations (by its atmospheric forcing) and "returns" these variations as feedbacks or land surface features that are of high relevance to the people living on it. The strong coupling between land surface, atmosphere, hydrosphere and cryosphere makes an analysis of its performance characteristics challenging: the response and the state of the land surface strongly depend on the climatological context, and metrics of interactions or feedbacks, which are all difficult to define and observe (van den Hurk et al., 2011).

LS3MIP addresses these challenges by enhancing earlier diagnostic studies and experimental designs. Within the limits to which complex models such as ESMs can be evaluated with currently available observational evidence (see e.g., the interesting philosophical discussion on climate model evaluation by Lenhard and Winsberg, 2010) it will lead to enhanced understanding of the contribution of land surface treatment to overall climate model performance; give inspiration on how to optimize land surface parameterizations or their forcing; support the development of better forecasting tools, where initial conditions affect the trajectory of the forecast and can be used to optimize forecast skill; and, last but not least, provide a better historical picture of the evolution 
of our vital water resources during the recent century. In particular, LS3MIP will provide a solid benchmark for assessing water and climate related risks and trends therein. Given the critical importance of changes in land water availability and of impacts of changes in snow, soil moisture and land surface states for the projected evolution of climate mean and extremes, we expect that LS3MIP will help the research community make fundamental advances in this area.

\section{Data availability}

The offline forcing data for the Land-Hist experiments and output from the model simulations described in this paper will be distributed through the Earth System Grid Federation (ESGF) with digital object identifiers (DOIs) assigned. The model output required for LS3MIP is listed in the Appendix. Model data distributed via ESGF will be freely accessible through data portals after registration. This infrastructure makes it possible to carry out the experiments in a distributed matter, and to allow later participation of additional modeling groups. Links to all forcings data sets will be made available via the CMIP Panel website ${ }^{17}$. Information about accreditation, data infrastructure, metadata structure, citation and acknowledging is provided by Eyring et al. (2016).

\footnotetext{
${ }^{17}$ http://www.wcrp-climate.org/index.php/wgcm-cmip/ about-cmip
} 


\section{Appendix A: Output data tables requested for LS3MIP}

Table A1. Variable request table "LEday": daily variables related to the energy cycle. Priority index ( $\left.p^{*}\right)$ in column 1 indicates $1:$ : Mandatory" and 2: "Desirable". The dimension (dim.) column indicates $T$ : time, $Y$ : latitude, $X$ : longitude, and $Z$ : soil or snow layers. "Direction" identifies the direction of positive numbers.

\begin{tabular}{|c|c|c|c|c|c|c|}
\hline$p^{*}$ & Name & standard_name (cf) & long_name (netCDF) & Unit & Direction & Dim. \\
\hline 1 & rss & surface_net_downward_shortwave_flux & net shortwave radiation & $\mathrm{W} \mathrm{m}^{-2}$ & downward & $T Y X$ \\
\hline 1 & rls & surface_net_downward_longwave_flux & net longwave radiation & $\mathrm{W} \mathrm{m}^{-2}$ & downward & $T Y X$ \\
\hline 2 & rsds & surface_downwelling_shortwave_flux_in_air & downward shortwave radiation & $\mathrm{W} \mathrm{m}^{-2}$ & downward & $T Y X$ \\
\hline 2 & rlds & surface_downwelling_longwave_flux_in_air & downward longwave radiation & $\mathrm{W} \mathrm{m}^{-2}$ & downward & $T Y X$ \\
\hline 2 & rsus & surface_upwelling_shortwave_flux_in_air & upward shortwave radiation & $\mathrm{W} \mathrm{m}^{-2}$ & upward & $T Y X$ \\
\hline 2 & rlus & surface_upwelling_longwave_flux_in_air & upward longwave radiation & $\mathrm{W} \mathrm{m}^{-2}$ & upward & $T Y X$ \\
\hline 1 & hfls & surface_upward_latent_heat_flux & latent heat flux & $\mathrm{W} \mathrm{m}^{-2}$ & upward & $T Y X$ \\
\hline 1 & hfss & surface_upward_sensible_heat_flux & sensible heat flux & $\mathrm{W} \mathrm{m}^{-2}$ & upward & $T Y X$ \\
\hline 1 & hfds & surface_downward_heat_flux & ground heat flux & $\mathrm{W} \mathrm{m}^{-2}$ & downward & $T Y X$ \\
\hline 1 & hfdsn & surface_downeard_heat_flux_in_snow & downward heat flux into snow & $\mathrm{W} \mathrm{m}^{-2}$ & downward & $T Y X$ \\
\hline 2 & hfmlt & surface_snow_and_ice_melt_heat_flux & energy of fusion & $\mathrm{W} \mathrm{m}^{-2}$ & solid to liquid & $T Y X$ \\
\hline 2 & hfsbl & surface_snow_and_ice_sublimation_heat_flux & energy of sublimation & $\mathrm{W} \mathrm{m}^{-2}$ & solid to vapor & $T Y X$ \\
\hline 2 & tau & surface_downward_stress & momentum flux & $\mathrm{Nm}^{-2}$ & downward & $T Y X$ \\
\hline 2 & hfrs & $\begin{array}{l}\text { temperature_flux_due_to_rainfall_expressed_ } \\
\text { as_heat_flux_onto_snow_and_ice }\end{array}$ & heat transferred to snowpack by rainfall & $\mathrm{W} \mathrm{m}^{-2}$ & downward & $T Y X$ \\
\hline 1 & dtes & $\begin{array}{l}\text { change_over_time_in_thermal_energy_ } \\
\text { content_of_surface }\end{array}$ & change in surface heat storage & $\mathrm{J} \mathrm{m}^{-2}$ & increase & $T Y X$ \\
\hline 1 & dtesn & $\begin{array}{l}\text { change_over_time_in_thermal_energy_ } \\
\text { content_of_surface_snow_and_ice }\end{array}$ & change in snow/ice cold content & $\mathrm{J} \mathrm{m}^{-2}$ & increase & $T Y X$ \\
\hline 1 & ts & surface_temperature & average surface temperature & $\mathrm{K}$ & - & $T Y X$ \\
\hline 2 & tsns & surface_snow_skin_temperature & snow surface temperature & $\mathrm{K}$ & - & $T Y X$ \\
\hline 2 & $\operatorname{tcs}$ & surface_canopy_skin_temperature & vegetation canopy temperature & $\mathrm{K}$ & - & $T Y X$ \\
\hline 2 & $\operatorname{tgs}$ & surface_ground_skin_temperature & temperature of bare soil & $\mathrm{K}$ & - & $T Y X$ \\
\hline 2 & $\operatorname{tr}$ & surface_radiative_temperature & surface radiative temperature & K & - & $T Y X$ \\
\hline 1 & albs & surface_albedo & surface albedo & - & - & $T Y X$ \\
\hline 1 & albsn & snow_and_ice_albedo & snow albedo & - & - & $T Y X$ \\
\hline 1 & snc & surface_snow_area_fraction & snow covered fraction & - & - & $T Y X$ \\
\hline 2 & albc & canopy_albedo & canopy albedo & - & - & $T Y X$ \\
\hline 2 & $\mathrm{cnc}$ & surface_canopy_area_fraction & canopy covered fraction & - & - & $T Y X$ \\
\hline 1 & tsl & soil_temperature & average layer soil temperature & $\mathrm{K}$ & & $T Z Y X$ \\
\hline 1 & tsnl & snow_temperature & temperature profile in the snow & $\mathrm{K}$ & - & $T Z Y X$ \\
\hline 1 & tasmax & air_temperature_maximum & $\begin{array}{l}\text { daily maximum near-surface air } \\
\text { temperature }\end{array}$ & $\mathrm{K}$ & - & $T Y X$ \\
\hline 1 & tasmin & air_temperature_minimum & $\begin{array}{l}\text { daily minimum near-surface air } \\
\text { temperature }\end{array}$ & $\mathrm{K}$ & - & $T Y X$ \\
\hline 2 & clt & cloud_area_fraction & total cloud fraction & - & - & $T Y X$ \\
\hline
\end{tabular}


Table A2. Variable request table "LWday": daily variables related to the water cycle.

\begin{tabular}{|c|c|c|c|c|c|c|}
\hline$p^{*}$ & Name & standard_name (cf) & long_name (netCDF) & Unit & Direction & Dim. \\
\hline 1 & $\mathrm{pr}$ & precipitation_flux & precipitation rate & $\mathrm{kg} \mathrm{m}^{-2} \mathrm{~s}^{-1}$ & downward & $T Y X$ \\
\hline 2 & prra & rainfall_flux & rainfall rate & $\mathrm{kg} \mathrm{m}^{-2} \mathrm{~s}^{-1}$ & downward & $T Y X$ \\
\hline 2 & prsn & snowfall_flux & snowfall rate & $\mathrm{kg} \mathrm{m}^{-2} \mathrm{~s}^{-1}$ & downward & $T Y X$ \\
\hline 2 & prrc & convective_rainfall_flux & convective rainfall rate & $\mathrm{kg} \mathrm{m}^{-2} \mathrm{~s}^{-1}$ & downward & $T Y X$ \\
\hline 2 & prsnc & convective_snowfall_flux & convective snowfall rate & $\mathrm{kg} \mathrm{m}^{-2} \mathrm{~s}^{-1}$ & downward & $T Y X$ \\
\hline 1 & prveg & precipitation_flux_onto_canopy & precipitation onto canopy & $\mathrm{kg} \mathrm{m}^{-2} \mathrm{~s}^{-1}$ & downward & $T Y X$ \\
\hline 1 & et & surface_evapotranspiration & total evapotranspiration & $\mathrm{kg} \mathrm{m}^{-2} \mathrm{~s}^{-1}$ & upward & $T Y X$ \\
\hline 1 & $\mathrm{ec}$ & liquid_water_evaporation_flux_from_canopy & interception evaporation & $\mathrm{kg} \mathrm{m}^{-2} \mathrm{~s}^{-1}$ & upward & $T Y X$ \\
\hline 1 & $\operatorname{tran}$ & Transpiration & vegetation transpiration & $\mathrm{kg} \mathrm{m}^{-2} \mathrm{~s}^{-1}$ & upward & $T Y X$ \\
\hline 1 & es & liquid_water_evaporation_flux_from_soil & bare soil evaporation & $\mathrm{kg} \mathrm{m}^{-2} \mathrm{~s}^{-1}$ & upward & $T Y X$ \\
\hline 2 & eow & liquid_water_evaporation_flux_from_open_water & open water evaporation & $\mathrm{kg} \mathrm{m}^{-2} \mathrm{~s}^{-1}$ & upward & $T Y X$ \\
\hline 2 & esn & liquid_water_evaporation_flux_from_surface_snow & snow evaporation & $\mathrm{kg} \mathrm{m}^{-2} \mathrm{~s}^{-1}$ & upward & $T Y X$ \\
\hline 2 & $\mathrm{sbl}$ & surface_snow_and_ice_sublimation_flux & snow sublimation & $\mathrm{kg} \mathrm{m}^{-2} \mathrm{~s}^{-1}$ & upward & $T Y X$ \\
\hline 2 & slbnosn & sublimation_amount_assuming_no_snow & sublimation of the snow free area & $\mathrm{kg} \mathrm{m}^{-2} \mathrm{~s}^{-1}$ & upward & $T Y X$ \\
\hline 2 & potet & water_potential_evapotranspiration_flux & potential evapotranspiration & $\mathrm{kg} \mathrm{m}^{-2} \mathrm{~s}^{-1}$ & upward & $T Y X$ \\
\hline 1 & mrro & runoff_flux & total runoff & $\mathrm{kg} \mathrm{m}^{-2} \mathrm{~s}^{-1}$ & out & $T Y X$ \\
\hline 2 & mrros & surface_runoff_flux & surface runoff & $\mathrm{kg} \mathrm{m}^{-2} \mathrm{~s}^{-1}$ & out & $T Y X$ \\
\hline 1 & mrrob & subsurface_runoff_flux & subsurface runoff & $\mathrm{kg} \mathrm{m}^{-2} \mathrm{~s}^{-1}$ & out & $T Y X$ \\
\hline 1 & $\mathrm{snm}$ & surface_snow_and_ice_melt_flux & snowmelt & $\mathrm{kg} \mathrm{m}^{-2} \mathrm{~s}^{-1}$ & solid to liquid & $T Y X$ \\
\hline 1 & snrefr & surface_snow_and_ice_refreezing_flux & refreezing of water in the snow & $\mathrm{kg} \mathrm{m}^{-2} \mathrm{~s}^{-1}$ & liquid to solid & $T Y X$ \\
\hline 2 & snmsl & surface_snow_melt_flux_into_soil_layer & water flowing out of snowpack & $\mathrm{kg} \mathrm{m}^{-2} \mathrm{~s}^{-1}$ & out & $T Y X$ \\
\hline 2 & qgwr & water_flux_from_soil_layer_to_groundwater & $\begin{array}{l}\text { groundwater recharge from } \\
\text { soil layer }\end{array}$ & $\mathrm{kg} \mathrm{m}^{-2} \mathrm{~s}^{-1}$ & out & $T Y X$ \\
\hline 2 & rivo & water_flux_from_upstream & river inflow & $\mathrm{m}^{3} \mathrm{~s}^{-1}$ & in & $T Y X$ \\
\hline 2 & rivi & water_flux_to_downstream & river discharge & $\mathrm{m}^{3} \mathrm{~s}^{-1}$ & out & $T Y X$ \\
\hline 1 & dslw & change_over_time_in_water_content_of_soil_layer & change in soil moisture & $\mathrm{kg} \mathrm{m}^{-2}$ & increase & $T Y X$ \\
\hline 1 & dsn & change_over_time_in_surface_snow_and_ice_amount & change in snow water equivalent & $\mathrm{kg} \mathrm{m}^{-2}$ & increase & $T Y X$ \\
\hline 1 & dsw & change_over_time_in_surface_water_amount & change in surface water storage & $\mathrm{kg} \mathrm{m}^{-2}$ & increase & $T Y X$ \\
\hline 1 & dcw & change_over_time_in_canopy_water_amount & change in interception storage & $\mathrm{kg} \mathrm{m}^{-2}$ & increase & $T Y X$ \\
\hline 2 & dgw & change_over_time_in_groundwater & change in groundwater & $\mathrm{kg} \mathrm{m}^{-2}$ & increase & $T Y X$ \\
\hline 2 & drivw & change_over_time_in_river_water_amount & change in river storage & $\mathrm{kg} \mathrm{m}^{-2}$ & increase & $T Y X$ \\
\hline 1 & rzwc & water_content_of_root_zone & root zone soil moisture & $\mathrm{kg} \mathrm{m}^{-2}$ & - & $T Y X$ \\
\hline 1 & $\mathrm{cw}$ & canopy_water_amount & total canopy water storage & $\mathrm{kg} \mathrm{m}^{-2}$ & - & $T Y X$ \\
\hline 1 & snw & surface_snow_amount & snow water equivalent & $\mathrm{kg} \mathrm{m}^{-2}$ & - & $T Z Y X$ \\
\hline 1 & snwc & canopy_snow_amount & SWE intercepted by the vegetation & $\mathrm{kg} \mathrm{m}^{-2}$ & - & $T Y X$ \\
\hline 2 & lwsnl & liquid_water_content_of_snow_layer & liquid water in snow pack & $\mathrm{kg} \mathrm{m}^{-2}$ & - & $T Z Y X$ \\
\hline 1 & sw & surface_water_amount_assuming_no_snow & surface water storage & $\mathrm{kg} \mathrm{m}^{-2}$ & - & $T Y X$ \\
\hline 1 & mrlsl & moisture_content_of_soil_layer & average layer soil moisture & $\mathrm{kg} \mathrm{m}^{-2}$ & - & $T Z Y X$ \\
\hline 1 & mrsos & moisture_content_of_soil_layer & moisture in top soil $(10 \mathrm{~cm})$ layer & $\mathrm{kg} \mathrm{m}^{-2}$ & - & $T Y X$ \\
\hline 1 & mrsow & relative_soil_moisture_content_above_field_capacity & total soil wetness & - & - & $T Y X$ \\
\hline 2 & wtd & depth_of_soil_moisture_saturation & water table depth & $\mathrm{m}$ & - & $T Y X$ \\
\hline 1 & tws & canopy_and_surface_and_subsurface_water_amount & terrestrial water storage & $\mathrm{kg} \mathrm{m}^{-2}$ & - & $T Y X$ \\
\hline 2 & mrlqso & mass_fraction_of_unfrozen_water_in_soil_layer & $\begin{array}{l}\text { average layer fraction of } \\
\text { liquid moisture }\end{array}$ & - & - & $T Z Y X$ \\
\hline 1 & mrfsofr & mass_fraction_of_frozen_water_in_soil_layer & $\begin{array}{l}\text { average layer fraction of } \\
\text { frozen moisture }\end{array}$ & - & - & $T Z Y X$ \\
\hline 2 & prrsn & mass_fraction_of_rainfall_onto_snow & fraction of rainfall on snow. & - & - & $T Y X$ \\
\hline 2 & prsnsn & mass_fraction_of_snowfall_onto_snow & fraction of snowfall on snow. & - & - & $T Y X$ \\
\hline 1 & lqsn & mass_fraction_of_liquid_water_in_snow & snow liquid fraction & - & - & $T Z Y X$ \\
\hline 1 & snd & surface_snow_thickness & depth of snow layer & $\mathrm{m}$ & - & $T Y X$ \\
\hline 1 & agesno & age_of_surface_snow & snow age & day & - & $T Y X$ \\
\hline 2 & sootsn & soot_content_of_surface_snow & snow soot content & $\mathrm{kg} \mathrm{m}^{-2}$ & - & $T Y X$ \\
\hline 2 & sic & sea_ice_area_fraction & ice-covered fraction & - & - & $T Y X$ \\
\hline 2 & sit & sea_ice_thickness & sea-ice thickness & $\mathrm{m}$ & - & $T Y X$ \\
\hline 2 & dfr & depth_of_frozen_soil & frozen soil depth & $\mathrm{m}$ & downward & $T Y X$ \\
\hline 2 & dmlt & depth_of_subsurface_melting & depth to soil thaw & $\mathrm{m}$ & downward & $T Y X$ \\
\hline 2 & tpf & permafrost_layer_thickness & permafrost layer thickness & $\mathrm{m}$ & - & $T Y X$ \\
\hline \multirow[t]{2}{*}{2} & pflw & liquid_water_content_of_permafrost_layer & $\begin{array}{l}\text { liquid water content of } \\
\text { permafrost layer }\end{array}$ & $\mathrm{kg} \mathrm{m}^{-2}$ & - & $T Y X$ \\
\hline & & & aerodynamic conductance & $\mathrm{ms}^{-1}$ & - & $T Y X$ \\
\hline 2 & ares & aerodynamic_resistance & aerodynamic resistance & $\mathrm{s} \mathrm{m}^{-1}$ & - & $T Y X$ \\
\hline
\end{tabular}


Table A2. Continued.

\begin{tabular}{lllllll}
\hline$p^{*}$ & Name & standard_name (cf) & long_name (netCDF) & Unit & Direction & Dim. \\
\hline 1 & nudgincw & nudging_increment_of_total_water & nudging increment of water & $\mathrm{kg} \mathrm{m}^{-2}$ & increase & TYX \\
1 & hur & relative_humidity & relative humidity & $\%$ & - & $T Y X$ \\
1 & hurmax & relative_humidity_maximum & $\begin{array}{l}\text { daily maximum near-surface } \\
\text { relative humidity }\end{array}$ & $\%$ & - & $T Y X$ \\
1 & hurmin & relative_humidity_minimum & $\begin{array}{l}\text { daily minimum near-surface } \\
\text { relative humidity }\end{array}$ & $\%$ & - & $T Y X$ \\
\hline
\end{tabular}

Table A3. Variable request table "LCmon": monthly variables related to the carbon cycle.

\begin{tabular}{|c|c|c|c|c|c|c|}
\hline$p^{*}$ & Name & standard_name (cf) & long_name (netCDF) & Unit & Direction & Dim. \\
\hline 1 & gpp & gross_primary_productivity_of_carbon & gross primary production & $\mathrm{kg} \mathrm{m}^{-2} \mathrm{~s}^{-1}$ & downward & $T Y X$ \\
\hline 1 & npp & net_primary_productivity_of_carbon & net primary production & $\mathrm{kg} \mathrm{m}^{-2} \mathrm{~s}^{-1}$ & downward & $T Y X$ \\
\hline 1 & nep & $\begin{array}{l}\text { surface_net_downward_mass_flux_of_carbon_ } \\
\text { dioxide_expressed_as_carbon_due_to_all_land_ } \\
\text { processes_excluding_anthropogenic_land_use_change }\end{array}$ & net ecosystem exchange & $\mathrm{kg} \mathrm{m}^{-2} \mathrm{~s}^{-1}$ & downward & $T Y X$ \\
\hline 1 & ra & plant_respiration_carbon_flux & autotrophic respiration & $\mathrm{kg} \mathrm{m}^{-2} \mathrm{~s}^{-1}$ & upward & $T Y X$ \\
\hline 1 & rh & heterotrophic_respiration_carbon_flux & heterotrophic respiration & $\mathrm{kg} \mathrm{m}^{-2} \mathrm{~s}^{-1}$ & upward & $T Y X$ \\
\hline 1 & fLuc & $\begin{array}{l}\text { surface_net_upward_mass_flux_of_carbon_- } \\
\text { dioxide_expressed_as_carbon_due_to_emission_ } \\
\text { from_anthropogenic_land_use_change }\end{array}$ & $\begin{array}{l}\text { net carbon mass flux into } \\
\text { atmosphere due to land use } \\
\text { change }\end{array}$ & $\mathrm{kg} \mathrm{m}^{-2} \mathrm{~s}^{-1}$ & upward & $T Y X$ \\
\hline 1 & cSoil & soil_carbon_content & carbon mass in soil pool & $\mathrm{kg} \mathrm{m}^{-2}$ & - & $T Y X$ \\
\hline 1 & cLitter & litter_carbon_content & carbon mass in litter pool & $\mathrm{kg} \mathrm{m}^{-2}$ & - & $T Y X$ \\
\hline 1 & cVeg & vegetation_carbon_content & carbon mass in vegetation & $\mathrm{kg} \mathrm{m}^{-2}$ & - & $T Y X$ \\
\hline 1 & cProduct & $\begin{array}{l}\text { carbon_content_of_products_of_ } \\
\text { anthropogenic_land_use_change }\end{array}$ & $\begin{array}{l}\text { carbon mass in products of } \\
\text { land use change }\end{array}$ & $\mathrm{kg} \mathrm{m}^{-2}$ & - & $T Y X$ \\
\hline 2 & cLeaf & leaf_carbon_content & carbon mass in leaves & $\mathrm{kg} \mathrm{m}^{-2}$ & - & $T Y X$ \\
\hline 2 & cWood & wood_carbon_content & carbon mass in wood & $\mathrm{kg} \mathrm{m}^{-2}$ & - & $T Y X$ \\
\hline 2 & cRoot & root_carbon_content & carbon mass in roots & $\mathrm{kg} \mathrm{m}^{-2}$ & - & $T Y X$ \\
\hline 2 & cMisc & miscellaneous_living_matter_carbon_content & $\begin{array}{l}\text { carbon mass in other living } \\
\text { compartments on land }\end{array}$ & $\mathrm{kg} \mathrm{m}^{-2}$ & - & $T Y X$ \\
\hline 2 & fVegLitter & litter_carbon_flux & $\begin{array}{l}\text { total carbon mass flux from } \\
\text { vegetation to litter }\end{array}$ & $\mathrm{kg} \mathrm{m}^{-2} \mathrm{~s}^{-1}$ & - & $T Y X$ \\
\hline 2 & fLitterSoil & carbon_mass_flux_into_soil_from_litter & $\begin{array}{l}\text { total carbon mass flux from } \\
\text { litter to soil }\end{array}$ & $\mathrm{kg} \mathrm{m}^{-2} \mathrm{~s}^{-1}$ & - & $T Y X$ \\
\hline 2 & fVegSoil & $\begin{array}{l}\text { carbon_mass_flux_into_soil_from_ } \\
\text { vegetation_excluding_litter }\end{array}$ & $\begin{array}{l}\text { total carbon mass flux from } \\
\text { vegetation directly to soil }\end{array}$ & $\mathrm{kg} \mathrm{m}^{-2} \mathrm{~s}^{-1}$ & - & $T Y X$ \\
\hline 1 & treeFrac & area_fraction & tree cover fraction & $\%$ & - & $T Y X$ \\
\hline 1 & grassFrac & area_fraction & natural grass fraction & $\%$ & - & $T Y X$ \\
\hline 1 & shrubFrac & area_fraction & shrub fraction & $\%$ & - & $T Y X$ \\
\hline 1 & cropFrac & area_fraction & crop fraction & $\%$ & - & $T Y X$ \\
\hline 1 & pastureFrac & area_fraction & anthropogenic pasture fraction & $\%$ & - & $T Y X$ \\
\hline 1 & baresoilFrac & area_fraction & bare soil fraction & $\%$ & - & $T Y X$ \\
\hline 1 & residualFrac & area_fraction & $\begin{array}{l}\text { fraction of grid cell that is } \\
\text { land but neither vegetation- } \\
\text { covered nor bare soil }\end{array}$ & $\%$ & - & $T Y X$ \\
\hline 1 & lai & leaf_area_index & leaf area index & $\mathrm{kg} \mathrm{m}^{-2}$ & - & $T Y X$ \\
\hline
\end{tabular}


Table A4. Variable request table "L3hr": 3-hourly variables to generate the atmospheric boundary conditions for the off-line simulation.

\begin{tabular}{|c|c|c|c|c|c|c|}
\hline$p^{*}$ & Name & standard_name (cf) & long_name (netCDF) & Unit & Direction & Dim. \\
\hline 1 & rsds & $\begin{array}{l}\text { surface_downwelling_ } \\
\text { shortwave_flux_in_air }\end{array}$ & downward shortwave radiation & $\mathrm{W} \mathrm{m}^{-2}$ & downward & $T Y X$ \\
\hline 1 & rlds & $\begin{array}{l}\text { surface_downwelling_ } \\
\text { longwave_flux_in_air }\end{array}$ & downward longwave radiation & $\mathrm{W} \mathrm{m} \mathrm{m}^{-2}$ & downward & $T Y X$ \\
\hline 1 & hus & specific_humidity & near-surface specific humidity & $\mathrm{kg} \mathrm{kg}^{-1}$ & - & $T Y X$ \\
\hline 1 & ta & air_temperature & near-surface air temperature & $\mathrm{K}$ & - & $T Y X$ \\
\hline 1 & ps & surface_air_pressure & surface pressure & $\mathrm{Pa}$ & - & $T Y X$ \\
\hline 1 & ws & wind_speed & near-surface wind speed & $\mathrm{ms}^{-1}$ & - & $T Y X$ \\
\hline 2 & va & northward_wind & near-surface northward wind component & $\mathrm{ms}^{-1}$ & northward & $T Y X$ \\
\hline 2 & ua & eastward_wind & near-surface eastward wind component & $\mathrm{m} \mathrm{s}^{-1}$ & eastward & $T Y X$ \\
\hline 2 & $\mathrm{pr}$ & precipitation_flux & precipitation rate & $\mathrm{kg} \mathrm{m}^{-2} \mathrm{~s}^{-1}$ & downward & $T Y X$ \\
\hline 1 & prra & rainfall_flux & rainfall rate & $\mathrm{kg} \mathrm{m}^{-2} \mathrm{~s}^{-1}$ & downward & $T Y X$ \\
\hline 1 & prsn & snowfall_flux & snowfall rate & $\mathrm{kg} \mathrm{m}^{-2} \mathrm{~s}^{-1}$ & downward & $T Y X$ \\
\hline 2 & prrc & convective_rainfall_flux & convective rainfall rate & $\mathrm{kg} \mathrm{m}^{-2} \mathrm{~s}^{-1}$ & downward & $T Y X$ \\
\hline 2 & prsnc & convective_snowfall_flux & convective snowfall rate & $\mathrm{kg} \mathrm{m}^{-2} \mathrm{~s}^{-1}$ & downward & $T Y X$ \\
\hline 1 & clt & cloud_area_fraction & total cloud fraction & - & - & $T Y X$ \\
\hline 2 & $\operatorname{co} 2 \mathrm{c}$ & $\begin{array}{l}\text { mole_fraction_of_carbon_ } \\
\text { dioxide_in_air }\end{array}$ & near-surface $\mathrm{CO}_{2}$ concentration & - & - & $T Y X$ \\
\hline
\end{tabular}


Acknowledgements. The authors thank the CMIP panel of the WCRP Working Group on Climate Modelling for their efforts in coordinating the CMIP6 enterprise. Graham P. Weedon was supported by the Joint UK DECC/Defra Met Office Hadley Climate Centre Programme (GA01101). Jiafu Mao is supported by the Biogeochemistry-Climate Feedbacks Scientific Focus Area project funded through the Regional and Global Climate Modeling Program in Climate and Environmental Sciences Division (CESD) of the Biological and Environmental Research (BER) Program in the U.S. Department of Energy (DOE) Office of Science. Oak Ridge National Laboratory is managed by UT-BATTELLE for DOE under contract DE-AC05-00OR22725. H. Kim and T. Oki were supported by Japan Society for the Promotion of Science KAKENHI (16H06291). Hanna Lee (NorESM) has expressed intention to participate in LS3MIP when feasible, but has not contributed to this manuscript.

Edited by: J. Kala

Reviewed by: P. Dirmeyer, G. Abramowitz, and one anonymous referee

\section{References}

Anav, A., Friedlingstein, P., Kidston, M., Bopp, L., Ciais, P., Cox, P., Jones, C., Jung, M., Myneni, R., and Zhu, Z.: Evaluating the Land and Ocean Components of the Global Carbon Cycle in the CMIP5 Earth System Models, J. Climate, 26, 6801-6843, doi:10.1175/JCLI-D-12-00417.1, 2013.

Baldocchi, D., Falge, E., Gu, L., Olson, R., Hollinger, D., Running, S., Anthoni, P., Bernhofer, C., Davis, K., Evans, R., Fuentes, J., Goldstein, A., Katul, G., Law, B., Lee, X., Malhi, Y., Meyers, T., Munger, W., Oechel, W., Paw, K. T., Pilegaard, K., Schmid, H. P., Valentini, R., Verma, S., Vesala, T., Wilson, K., and Wofsy, S.: FLUXNET: A New Tool to Study the Temporal and Spatial Variability of EcosystemScale Carbon Dioxide, Water Vapor, and Energy Flux Densities, B. Am. Meteorol. Soc., 82, 2415-2434, doi:10.1175/15200477(2001)082<2415:FANTTS>2.3.CO;2, 2001.

Best, M. J., Abramowitz, G., Johnson, H. R., Pitman, A. J., Balsamo, G., Boone, A., Cuntz, M., Decharme, B., Dirmeyer, P. A., Dong, J., Ek, M., Guo, Z., Haverd, V., van den Hurk, B. J. J., Nearing, G. S., Pak, B., Peters-Lidard, C., Santanello, J. A., Stevens, L., and Vuichard, N.: The Plumbing of Land Surface Models: Benchmarking Model Performance, J. Hydrometeorol., 16, 1425-1442, doi:10.1175/JHM-D-14-0158.1, 2015.

Boone, A., Decharme, B., Guichard, F., de Rosnay, P., Balsamo, G., Beljaars, A., Chopin, F., Orgeval, T., Polcher, J., Delire, C., Ducharne, A., Gascoin, S., Grippa, M., Jarlan, L., Kergoat, L., Mougin, E., Gusev, Y., Nasonova, O., Harris, P., Taylor, C., Norgaard, A., Sandholt, I., Ottlé, C., Poccard-Leclercq, I., SauxPicart, S., and Xue, Y.: The AMMA Land Surface Model Intercomparison Project (ALMIP), B. Am. Meteorol. Soc., 90, 18651880, doi:10.1175/2009BAMS2786.1, 2009.

Brown, R. D. and Mote, P. W.: The Response of Northern Hemisphere Snow Cover to a Changing Climate, J. Climate, 22, 2124 2145, doi:10.1175/2008JCLI2665.1, 2009.

Brutel-Vuilmet, C., Ménégoz, M., and Krinner, G.: An analysis of present and future seasonal Northern Hemisphere land snow cover simulated by CMIP5 coupled climate models, The Cryosphere, 7, 67-80, doi:10.5194/tc-7-67-2013, 2013.

Campoy, A., Ducharne, A., Cheruy, F., Hourdin, F., Polcher, J., and Dupont, J. C.: Response of land surface fluxes and precipitation to different soil bottom hydrological conditions in a general circulation model, J. Geophys. Res.-Atmos., 118, 10725-10739, doi:10.1002/jgrd.50627, 2013.

Carmack, E., Yamamoto-Kawai, M., Haine, T., Bacon, S., Bluhm, B., Lique, C., Melling, H., Polyakov, I., Straneo, F., Timmermans, M.-L., and Williams, W.: Fresh water and its role in the Arctic Marine System: sources, disposition, storage, export, and physical and biogeochemical consequences in the Arctic and global oceans, J. Geophys. Res.-Biogeo., 121, 675-717, doi:10.1002/2015JG003140, 2015.

Cattiaux, J., Douville, H., and Peings, Y.: European temperatures in CMIP5: origins of present-day biases and future uncertainties, Clim. Dynam., 41, 2889-2907, doi:10.1007/s00382-013-1731-y, 2013.

Cheruy, F., Dufresne, J. L., Hourdin, F., and Ducharne, A.: Role of clouds and land-atmosphere coupling in midlatitude continental summer warm biases and climate change amplification in CMIP5 simulations, Geophys. Res. Lett., 41, 6493-6500, doi:10.1002/2014GL061145, 2014.

Clark, M. P., Fan, Y., Lawrence, D. M., Adam, J. C., Bolster, D., Gochis, D. J., Hooper, R. P., Kumar, M., Leung, L. R., Mackay, D. S., Maxwell, R. M., Shen, C., Swenson, S. C., and Zeng, X.: Improving the representation of hydrologic processes in Earth System Models, Water Resour. Res., 51, 5929-5956, doi:10.1002/2015WR017096, 2015.

Compo, G. P., Whitaker, J. S., Sardeshmukh, P. D., Matsui, N., Allan, R. J., Yin, X., Gleason, B. E., Vose, R. S., Rutledge, G., Bessemoulin, P., Brönnimann, S., Brunet, M., Crouthamel, R. I., Grant, A. N., Groisman, P. Y., Jones, P. D., Kruk, M. C., Kruger, A. C., Marshall, G. J., Maugeri, M., Mok, H. Y., Nordli, Ø., Ross, T. F., Trigo, R. M., Wang, X. L., Woodruff, S. D., and Worley, S. J.: The Twentieth Century Reanalysis Project, Q. J. Roy. Meteor. Soc., 137, 1-28, doi:10.1002/qj.776, 2011.

Cox, P. M., Pearson, D., Booth, B. B., Friedlingstein, P., Huntingford, C., Jones, C. D., and Luke, C. M.: Sensitivity of tropical carbon to climate change constrained by carbon dioxide variability, Nature, 494, 341-344, doi:10.1038/nature11882, 2013.

Dai, A. and Trenberth, K. E.: Estimates of Freshwater Discharge from Continents: Latitudinal and Seasonal Variations, J. Hydrometeorol., 3, 660-687, doi:10.1175/15257541(2002)003<0660:EOFDFC>2.0.CO;2, 2002.

Derksen, C. and Brown, R.: Spring snow cover extent reductions in the 2008-2012 period exceeding climate model projections, Geophys. Res. Lett., 39, L19504, doi:10.1029/2012GL053387, 2012.

Dirmeyer, P. A., Dolman, A. J., and Sato, N.: The Pilot Phase of the Global Soil Wetness Project, B. Am. Meteorol. Soc., 80, 851-878, doi:10.1175/15200477(1999)080<0851:TPPOTG>2.0.CO;2, 1999.

Dirmeyer, P. A., Gao, X., Zhao, M., Guo, Z., Oki, T., and Hanasaki, N.: GSWP-2: Multimodel Analysis and Implications for Our Perception of the Land Surface, B. Am. Meteorol. Soc., 87, 13811397, doi:10.1175/BAMS-87-10-1381, 2006.

Dirmeyer, P. A., Kumar, S., Fennessy, M. J., Altshuler, E. L., DelSole, T., Guo, Z., Cash, B. A., and Straus, D.: Model Esti- 
mates of Land-Driven Predictability in a Changing Climate from CCSM4, J. Climate, 26, 8495-8512, doi:10.1175/JCLI-D-13$00029.1,2013$.

Dirmeyer, P. A., Peters-Lidard, C., and Balsamo, G.: LandAtmosphere Interactions and the Water Cycle, Seamless prediction of the Earth system: from minutes to months, edited by: Brunet, G., Jones, S., and Ruti, P. M., Vol. 1156, chap. 15, WMO, Geneva, Switzerland, 2015.

Dorigo, W., de Jeu, R., Chung, D., Parinussa, R., Liu, Y., Wagner, W., and Fernández-Prieto, D.: Evaluating global trends (19882010) in harmonized multi-satellite surface soil moisture, Geophys. Res. Lett., 39, L18405, doi:10.1029/2012GL052988, 2012.

Douville, H.: Assessing the Influence of Soil Moisture on Seasonal Climate Variability with AGCMs, J. Hydrometeorol., 4, 1044-1066, doi:10.1175/15257541(2003)004<1044:ATIOSM>2.0.CO;2, 2003.

Douville, H., Conil, S., Tyteca, S., and Voldoire, A.: Soil moisture memory and West African monsoon predictability: artefact or reality?, Clim. Dynam., 28, 723-742, doi:10.1007/s00382-0060207-8, 2007.

Douville, H., Ribes, A., Decharme, B., Alkama, R., and Sheffield, J.: Anthropogenic influence on multidecadal changes in reconstructed global evapotranspiration, Nat. Clim. Change, 3, 59-62, doi:10.1038/nclimate1632, 2013.

Douville, H., Colin, J., Krug, E., Cattiaux, J., and Thao, S.: Midlatitude daily summer temperatures reshaped by soil moisture under climate change, Geophys. Res. Lett., 43, 812-818, doi:10.1002/2015GL066222, 2016.

Essery, R., Rutter, N., Pomeroy, J., Baxter, R., Stähli, M., Gustafsson, D., Barr, A., Bartlett, P., and Elder, K.: SNOWMIP2: An Evaluation of Forest Snow Process Simulations, B. Am. Meteorol. Soc., 90, 1120-1135, doi:10.1175/2009BAMS2629.1, 2009.

Etchevers, P., Martin, E., Brown, R., Fierz, C., Lejeune, Y., Bazile, E., Boone, A., Dai, Y.-J., Essery, R., Fernandez, A., Gusev, Y., Jordan, R., Koren, V., Kowalczyk, E., Nasonova, N. O., Pyles, R. D., Schlosser, A., Shmakin, A. B., Smirnova, T. G., Strasser, U., Verseghy, D., Yamazaki, T., and Yang, Z.-L.: Validation of the energy budget of an alpine snowpack simulated by several snow models (SnowMIP project), Ann. Glaciol., 38, 150-158, doi:10.3189/172756404781814825, 2004.

Evans, J., Ji, F., Abramowitz, G., and Ekström, M.: Optimally choosing small ensemble members to produce robust climate simulations, Environ. Res. Lett., 8, 044050, doi:10.1088/17489326/8/4/044050, 2013.

Eyring, V., Bony, S., Meehl, G. A., Senior, C. A., Stevens, B., Stouffer, R. J., and Taylor, K. E.: Overview of the Coupled Model Intercomparison Project Phase 6 (CMIP6) experimental design and organization, Geosci. Model Dev., 9, 1937-1958, doi:10.5194/gmd-9-1937-2016, 2016.

Flanner, M. G., Shell, K. M., Barlage, M., Perovich, D. K., and Tschudi, M. A.: Radiative forcing and albedo feedback from the Northern Hemisphere cryosphere between 1979 and 2008, Nat. Geosci., 4, 151-155, doi:10.1038/ngeo1062, 2011.

Fletcher, C. G., Zhao, H., Kushner, P. J., and Fernandes, R.: Using models and satellite observations to evaluate the strength of snow albedo feedback, J. Geophys. Res.-Atmos., 117, D11117, doi:10.1029/2012JD017724, 2012.

Friedlingstein, P., Meinshausen, M., Arora, V. K., Jones, C. D., Anav, A., Liddicoat, S. K., and Knutti, R.: Uncertainties in
CMIP5 Climate Projections due to Carbon Cycle Feedbacks, J. Climate, 27, 511-526, doi:10.1175/JCLI-D-12-00579.1, 2013.

Gobron, N., Belward, A., Pinty, B., and Knorr, W.: Monitoring biosphere vegetation 1998-2009, Geophys. Res. Lett., 37, L15402, doi:10.1029/2010GL043870, 2010.

Gouttevin, I., Menegoz, M., Dominé, F., Krinner, G., Koven, C., Ciais, P., Tarnocai, C., and Boike, J.: How the insulating properties of snow affect soil carbon distribution in the continental pan-Arctic area, J. Geophys. Res.-Biogeo., 117, G02020, doi:10.1029/2011JG001916, 2012.

Gregory, J. M., Bouttes-Mauhourat, N., Griffies, S. M., Haak, H., Hurlin, W. J., Jungclaus, J., Kelley, M., Lee, W. G., Marshall, J., Romanou, A., Saenko, O. A., Stammer, D., and Winton, M.: The Flux-Anomaly-Forced Model Intercomparison Project (FAFMIP) contribution to CMIP6: Investigation of sea-level and ocean climate change in response to $\mathrm{CO}_{2}$ forcing, Geosci. Model Dev. Discuss., doi:10.5194/gmd-2016-122, in review, 2016.

Greve, P., Orlowsky, B., Mueller, B., Sheffield, J., Reichstein, M., and Seneviratne, S. I.: Global assessment of trends in wetting and drying over land, Nat. Geosci., 7, 716-721, 2014.

Griffies, S. M., Danabasoglu, G., Durack, P. J., Adcroft, A. J., Balaji, V., Böning, C. W., Chassignet, E. P., Curchitser, E., Deshayes, J., Drange, H., Fox-Kemper, B., Gleckler, P. J., Gregory, J. M., Haak, H., Hallberg, R. W., Hewitt, H. T., Holland, D. M., Ilyina, T., Jungclaus, J. H., Komuro, Y., Krasting, J. P., Large, W. G., Marsland, S. J., Masina, S., McDougall, T. J., Nurser, A. J. G., Orr, J. C., Pirani, A., Qiao, F., Stouffer, R. J., Taylor, K. E., Treguier, A. M., Tsujino, H., Uotila, P., Valdivieso, M., Winton, M., and Yeager, S. G.: Experimental and diagnostic protocol for the physical component of the CMIP6 Ocean Model Intercomparison Project (OMIP), Geosci. Model Dev. Discuss., doi:10.5194/gmd-2016-77, in review, 2016.

Guo, Z. and Dirmeyer, P. A.: Interannual Variability of LandAtmosphere Coupling Strength, J. Hydrometeorol., 14, 16361646, doi:10.1175/JHM-D-12-0171.1, 2013.

Haddeland, I., Clark, D. B., Franssen, W., Ludwig, F., Voß, F., Arnell, N. W., Bertrand, N., Best, M., Folwell, S., Gerten, D., Gomes, S., Gosling, S. N., Hagemann, S., Hanasaki, N., Harding, R., Heinke, J., Kabat, P., Koirala, S., Oki, T., Polcher, J., Stacke, T., Viterbo, P., Weedon, G. P., and Yeh, P.: Multimodel Estimate of the Global Terrestrial Water Balance: Setup and First Results, J. Hydrometeorol., 12, 869-884, doi:10.1175/2011JHM1324.1, 2011.

Hall, A., Qu, X., and Neelin, J. D.: Improving predictions of summer climate change in the United States, Geophys. Res. Lett., 35, L01702, doi:10.1029/2007GL032012, 2008.

Hauser, M., Orth, R., and Seneviratne, S. I.: Role of soil moisture vs recent climate change for heat waves in western Russia, Geophys. Res. Lett., 43, 2819-2826, doi:10.1002/2016GL068036, 2016.

Hempel, S., Frieler, K., Warszawski, L., Schewe, J., and Piontek, F.: A trend-preserving bias correction - the ISI-MIP approach, Earth Syst. Dynam., 4, 219-236, doi:10.5194/esd-4-219-2013, 2013.

Hoffman, F. M., Randerson, J. T., Arora, V. K., Bao, Q., Cadule, P., Ji, D., Jones, C. D., Kawamiya, M., Khatiwala, S., Lindsay, K., Obata, A., Shevliakova, E., Six, K. D., Tjiputra, J. F., Volodin, E. M., and Wu, T.: Causes and implications of persistent atmospheric carbon dioxide biases in Earth System Models, J. Geo- 
phys. Res.-Biogeo., 119, 141-162, doi:10.1002/2013JG002381, 2014.

Holland, M. M. and Bitz, C. M.: Polar amplification of climate change in coupled models, Clim. Dynam., 21, 221-232, doi:10.1007/s00382-003-0332-6, 2003.

Hong, S.-Y. and Chang, E.-C.: Spectral nudging sensitivity experiments in a regional climate model, Asia-Pac. J. Atmos. Sci., 48, 345-355, doi:10.1007/s13143-012-0033-3, 2012.

Jaeger, E. B. and Seneviratne, S. I.: Impact of soil moistureatmosphere coupling on European climate extremes and trends in a regional climate model, Clim. Dynam., 36, 1919-1939, doi:10.1007/s00382-010-0780-8, 2011.

Jones, C. D., Arora, V., Friedlingstein, P., Bopp, L., Brovkin, V., Dunne, J., Graven, H., Hoffman, F., Ilyina, T., John, J. G., Jung, M., Kawamiya, M., Koven, C., Pongratz, J., Raddatz, T., Randerson, J., and Zaehle, S.: The C4MIP experimental protocol for CMIP6, Geosci. Model Dev. Discuss., doi:10.5194/gmd-201636, in review, 2016.

Jung, M., Reichstein, M., Ciais, P., Seneviratne, S. I., Sheffield, J., Goulden, M. L., Bonan, G., Cescatti, A., Chen, J., de Jeu, R., Dolman, A. J., Eugster, W., Gerten, D., Gianelle, D., Gobron, N., Heinke, J., Kimball, J., Law, B. E., Montagnani, L., Mu, Q., Mueller, B., Oleson, K., Papale, D., Richardson, A. D., Roupsard, O., Running, S., Tomelleri, E., Viovy, N., Weber, U., Williams, C., Wood, E., Zaehle, S., and Zhang, K.: Recent decline in the global land evapotranspiration trend due to limited moisture supply, Nature, 467, 951-954, doi:10.1038/nature09396, 2010.

Kim, H.: Role of rivers in the spatiotemporal variations of terrestrial hydrological circulations, University of Tokyo, Tokyo, Japan, 2010.

Kim, H., Yeh, P. J.-F., Oki, T., and Kanae, S.: Role of rivers in the seasonal variations of terrestrial water storage over global basins, Geophys. Res. Lett., 36, L17402, doi:10.1029/2009GL039006, 2009.

Kim, H., Watanabe, S., Chang, E-.C., Yoshimura, K., Compo, G. P., Hirabayashi, Y., Famiglietti, J., and Oki, T.: A century-long global surface meteorology for offline terrestrial simulations, in preparation, 2016.

Koster, R. D., Suarez, M. J., and Heiser, M.: Variance and Predictability of Precipitation at Seasonal-to-Interannual Timescales, J. Hydrometeorol., 1, 26-46, doi:10.1175/15257541(2000)001<0026:VAPOPA>2.0.CO;2, 2000.

Koster, R. D., Guo, Z., Bonan, G., Chan, E., Cox, P., Gordon, C. T., Kanae, S., Kowalczyk, E., Lawrence, D., Liu, P., Lu, C.-H., Malyshev, S., McAvaney, B., Mitchell, K., Mocko, D., Oki, T., Oleson, K., Pitman, A., Sud, Y. C., Taylor, C. M., Verseghy, D., Vasic, R., Xue, Y., and Yamada, T.: Regions of Strong Coupling Between Soil Moisture and Precipitation, Science, 305, 11381140, doi:10.1126/science.1100217, 2004.

Koster, R. D., Sud, Y. C., Guo, Z., Dirmeyer, P. A., Bonan, G., Oleson, K. W., Chan, E., Verseghy, D., Cox, P., Davies, H., Kowalczyk, E., Gordon, C. T., Kanae, S., Lawrence, D., Liu, P., Mocko, D., Lu, C.-H., Mitchell, K., Malyshev, S., McAvaney, B., Oki, T., Yamada, T., Pitman, A., Taylor, C. M., Vasic, R., and Xue, Y.: GLACE: The Global Land-Atmosphere Coupling Experiment. Part I: Overview, J. Hydrometeorol., 7, 590-610, doi:10.1175/JHM510.1, 2006.
Koster, R. D., Mahanama, S. P. P., Yamada, T. J., Balsamo, G., Berg, A. A., Boisserie, M., Dirmeyer, P. A., Doblas-Reyes, F. J., Drewitt, G., Gordon, C. T., Guo, Z., Jeong, J.-H., Lawrence, D. M., Lee, W.-S., Li, Z., Luo, L., Malyshev, S., Merryfield, W. J., Seneviratne, S. I., Stanelle, T., van den Hurk, B. J. J. M., Vitart, F., and Wood, E. F.: Contribution of land surface initialization to subseasonal forecast skill: First results from a multi-model experiment, Geophys. Res. Lett., 37, L02402, doi:10.1029/2009GL041677, 2010a.

Koster, R. D., Mahanama, S. P. P., Livneh, B., Lettenmaier, D. P., and Reichle, R. H.: Skill in streamflow forecasts derived from large-scale estimates of soil moisture and snow, Nat. Geosci., 3, 613-616, doi:10.1038/ngeo944, 2010 b.

Koven, C. D., Riley, W. J., and Stern, A.: Analysis of Permafrost Thermal Dynamics and Response to Climate Change in the CMIP5 Earth System Models, J. Climate, 26, 1877-1900, doi:10.1175/JCLI-D-12-00228.1, 2012.

Lawrence, D. M., Hurtt, George C., Arneth, A., Brovkin, V., Calvin, K. V., Jones, Andrew D., Jones, C. D., Lawrence, P. J., de NobletDucoudré, N., Pongratz, J., Seneviratne, S. I., and Shevliakova, E.: The Land Use Model Intercomparison Project (LUMIP): Rationale and experimental design, Geosci. Model Dev. Discuss., doi:10.5194/gmd-2016-76, in review, 2016.

Lehning, M.: Snow-atmosphere interactions and hydrological consequences, Adv. Water Resour., 55, 1-3, doi:10.1016/j.advwatres.2013.02.001, 2013.

Lenhard, J. and Winsberg, E.: Holism, entrenchment, and the future of climate model pluralism, Stud. Hist. Philos. Sci. Part B, 41, 253-262, 2010.

Le Quéré, C., Raupach, M. R., Canadell, J. G., Marland, G., Bopp, L., Ciais, P., Conway, T. J., Doney, S. C., Feely, R. A., Foster, P., Friedlingstein, P., Gurney, K., Houghton, R. A., House, J. I., Huntingford, C., Levy, P. E., Lomas, M. R., Majkut, J., Metzl, N., Ometto, J. P., Peters, G. P., Prentice, I. C., Randerson, J. T., Running, S. W., Sarmiento, J. L., Schuster, U., Sitch, S., Takahashi, T., Viovy, N., van der Werf, G. R., and Woodward, F. I.: Trends in the sources and sinks of carbon dioxide, Nat. Geosci., 2, 831-836, doi:10.1038/ngeo689, 2009.

Liu, Y. Y., Dorigo, W. A., Parinussa, R. M., de Jeu, R. A. M., Wagner, W., McCabe, M. F., Evans, J. P., and van Dijk, A. I. J. M.: Trend-preserving blending of passive and active microwave soil moisture retrievals, Remote Sens. Environ., 123, 280-297, doi:10.1016/j.rse.2012.03.014, 2012.

Mao, J., Fu, W., Shi, X., Ricciuto, D. M., Fisher, J. B., Dickinson, R. E., Wei, Y., Shem, W., Piao, S., Wang, K., Schwalm, C. R., Tian, H., Mu, M., Arain, A., Ciais, P., Cook, R., Dai, Y., Hayes, D., Hoffman, F. M., Huang, M., Huang, S., Huntzinger, D. N., Ito, A., Jain, A., King, A. W., Lei, H., Lu, C., Michalak, A. M., Parazoo, N., Peng, C., Peng, S., Poulter, B., Schaefer, K., Jafarov, E., Thornton, P. E., Wang, W., Zeng, N., Zeng, Z., Zhao, F., Zhu, Q., and Zhu, Z.: Disentangling climatic and anthropogenic controls on global terrestrial evapotranspiration trends, Environ. Res. Lett., 10, 094008, doi:10.1088/1748-9326/10/9/094008, 2015.

Materia, S., Gualdi, S., Navarra, A., and Terray, L.: The effect of Congo River freshwater discharge on Eastern Equatorial Atlantic climate variability, Clim. Dynam., 39, 2109-2125, doi:10.1007/s00382-012-1514-x, 2012.

Meng, L., Paudel, R., Hess, P. G. M., and Mahowald, N. M.: Seasonal and interannual variability in wetland methane emissions 
simulated by CLM4Me' and CAM-chem and comparisons to observations of concentrations, Biogeosciences, 12, 4029-4049, doi:10.5194/bg-12-4029-2015, 2015.

Mudryk, L. R., Derksen, C., Kushner, P. J., and Brown, R.: Characterization of Northern Hemisphere Snow Water Equivalent Datasets, 1981-2010, J. Climate, 28, 8037-8051, doi:10.1175/JCLI-D-15-0229.1, 2015.

Mueller, B. and Seneviratne, S. I.: Systematic land climate and evapotranspiration biases in CMIP5 simulations, Geophys. Res. Lett., 41, 128-134, doi:10.1002/2013GL058055, 2014.

Mueller, B., Hirschi, M., Jimenez, C., Ciais, P., Dirmeyer, P. A., Dolman, A. J., Fisher, J. B., Jung, M., Ludwig, F., Maignan, F., Miralles, D. G., McCabe, M. F., Reichstein, M., Sheffield, J., Wang, K., Wood, E. F., Zhang, Y., and Seneviratne, S. I.: Benchmark products for land evapotranspiration: LandFluxEVAL multi-data set synthesis, Hydrol. Earth Syst. Sci., 17, 3707-3720, doi:10.5194/hess-17-3707-2013, 2013.

Mystakidis, S., Davin, E. L., Gruber, N., and Seneviratne, S. I.: Constraining future terrestrial carbon cycle projections using observation-based water and carbon flux estimates, Glob. Change Biol., 22, 2198-2215, doi:10.1111/gcb.13217, 2016.

O’Neill, B. C., Tebaldi, C., van Vuuren, D., Eyring, V., Friedlingstein, P., Hurtt, G., Knutti, R., Kriegler, E., Lamarque, J.-F., Lowe, J., Meehl, J., Moss, R., Riahi, K., and Sanderson, B. M.: The Scenario Model Intercomparison Project (ScenarioMIP) for CMIP6, Geosci. Model Dev. Discuss., doi:10.5194/gmd-201684, in review, 2016.

Orth, R. and Seneviratne, S. I.: Soil moisture and sea surface temperatures similarly important for land climate in the warm season in the Community Earth System Model, J. Climate, submitted, 2016.

Orth, R., Koster, R. D., and Seneviratne, S. I.: Inferring Soil Moisture Memory from Streamflow Observations Using a Simple Water Balance Model, J. Hydrometeorol., 14, 1773-1790, doi:10.1175/JHM-D-12-099.1, 2013.

Peings, Y., Douville, H., Alkama, R., and Decharme, B.: Snow contribution to springtime atmospheric predictability over the second half of the twentieth century, Clim. Dynam., 37, 985-1004, doi:10.1007/s00382-010-0884-1, 2011.

Perket, J., Flanner, M. G., and Kay, J. E.: Diagnosing shortwave cryosphere radiative effect and its 21 st century evolution in CESM, J. Geophys. Res.-Atmos., 119, 1356-1362, doi:10.1002/2013JD021139, 2014.

Qu, X. and Hall, A.: On the persistent spread in snow-albedo feedback, Clim. Dynam., 42, 69-81, doi:10.1007/s00382-013-1774$0,2014$.

Reager, J. T., Gardner, A. S., Famiglietti, J. S., Wiese, D. N., Eicker, A., and Lo, M.-H.: A decade of sea level rise slowed by climate-driven hydrology, Science, 351, 699-703, doi:10.1126/science.aad8386, 2016.

Rodell, M., Velicogna, I., and Famiglietti, J. S.: Satellite-based estimates of groundwater depletion in India, Nature, 460, 999-1002, doi:10.1038/nature08238, 2009.

Seneviratne, S. I., Luthi, D., Litschi, M., and Schar, C.: Landatmosphere coupling and climate change in Europe, Nature, 443, 205-209, doi:10.1038/nature05095, 2006.

Seneviratne, S. I., Corti, T., Davin, E. L., Hirschi, M., Jaeger, E. B., Lehner, I., Orlowsky, B., and Teuling, A. J.: Investigating soil moisture-climate interactions in a changing climate: A review, Earth-Sci. Rev., 99, 125-161, doi:10.1016/j.earscirev.2010.02.004, 2010.

Seneviratne, S. I., Wilhelm, M., Stanelle, T., van den Hurk, B., Hagemann, S., Berg, A., Cheruy, F., Higgins, M. E., Meier, A., Brovkin, V., Claussen, M., Ducharne, A., Dufresne, J.-L., Findell, K. L., Ghattas, J., Lawrence, D. M., Malyshev, S., Rummukainen, M., and Smith, B.: Impact of soil moistureclimate feedbacks on CMIP5 projections: First results from the GLACE-CMIP5 experiment, Geophys. Res. Lett., 40, 5212 5217, doi:10.1002/grl.50956, 2013.

Seneviratne, S. I., Van den Hurk, B., Lawrence, D. M., Krinner, G., Hurtt, G., Kim, H., Derksen, C., Oki, T., Boone, A., Ek, M., Brovkin, V., Dirmeyer, P. A., Douville, H., Friedlingstein, P., Hagemann, S., Koster, R. D., de Noblet-Ducoudre, N., and Pitman, A. J.: Land Processes, Forcings, and Feedbacks in Climate Change Simulations: The CMIP6 "LandMIPs.", GEWEX Newsl., Columbia, MD, USA, 6-10, 2014.

Seneviratne, S. I., Donat, M. G., Pitman, A. J., Knutti, R., and Wilby, R. L.: Allowable $\mathrm{CO}_{2}$ emissions based on regional and impact-related climate targets, Nature, 529, 477-483, 2016.

Sheffield, J., Goteti, G., and Wood, E. F.: Development of a 50Year High-Resolution Global Dataset of Meteorological Forcings for Land Surface Modeling, J. Climate, 19, 3088-3111, doi:10.1175/JCLI3790.1, 2006.

Sheffield, J., Wood, E. F., and Roderick, M. L.: Little change in global drought over the past 60 years, Nature, 491, 435-438, doi:10.1038/nature11575, 2012.

Singh, D., Flanner, M. G., and Perket, J.: The global land shortwave cryosphere radiative effect during the MODIS era, The Cryosphere, 9, 2057-2070, doi:10.5194/tc-9-2057-2015, 2015.

Sitch, S., Friedlingstein, P., Gruber, N., Jones, S. D., MurrayTortarolo, G., Ahlström, A., Doney, S. C., Graven, H., Heinze, C., Huntingford, C., Levis, S., Levy, P. E., Lomas, M., Poulter, B., Viovy, N., Zaehle, S., Zeng, N., Arneth, A., Bonan, G., Bopp, L., Canadell, J. G., Chevallier, F., Ciais, P., Ellis, R., Gloor, M., Peylin, P., Piao, S. L., Le Quéré, C., Smith, B., Zhu, Z., and Myneni, R.: Recent trends and drivers of regional sources and sinks of carbon dioxide, Biogeosciences, 12, 653679, doi:10.5194/bg-12-653-2015, 2015.

Thackeray, C. W., Fletcher, C. G., and Derksen, C.: Quantifying the skill of CMIP5 models in simulating seasonal albedo and snow cover evolution, J. Geophys. Res.-Atmos., 120, 58315849, doi:10.1002/2015JD023325, 2015.

Thomas, J., Berg, A., and Merryfield, W.: Influence of snow and soil moisture initialization on sub-seasonal predictability and forecast skill in boreal spring, Clim. Dynam., 47, 49-65, doi:10.1007/s00382-015-2821-9, 2016.

Trenberth, K. E., Dai, A., van der Schrier, G., Jones, P. D., Barichivich, J., Briffa, K. R., and Sheffield, J.: Global warming and changes in drought, Nat. Clim. Change, 4, 17-22, 2014.

van den Hurk, B., Best, M., Dirmeyer, P., Pitman, A., Polcher, J., and Santanello, J.: Acceleration of Land Surface Model Development over a Decade of Glass, B. Am. Meteorol. Soc., 92, 15931600, doi:10.1175/BAMS-D-11-00007.1, 2011.

van den Hurk, B., Doblas-Reyes, F., Balsamo, G., Koster, R., Seneviratne, S., and Camargo Jr., H.: Soil moisture effects on seasonal temperature and precipitation forecast scores in Europe, Clim. Dynam., 38, 349-362, doi:10.1007/s00382-010-0956-2, 2012. 
Viovy, N. and Ciais, P.: A combined dataset for ecosystem modelling, available at: http://esgf.extra.cea.fr/thredds/catalog/store/ p529viov/cruncep/catalog.html (last access: 1 August 2016), 2009.

Wada, Y., Beek, L. P., Sperna Weiland, F. C., Chao, B. F., Wu, Y., and Bierkens, M. F.: Past and future contribution of global groundwater depletion to sea-level rise, Geophys. Res. Lett., 39, L09402, doi:10.1029/2012GL051230, 2012.

Warszawski, L., Frieler, K., Huber, V., Piontek, F., Serdeczny, O., and Schewe, J.: The Inter-Sectoral Impact Model Intercomparison Project (ISI-MIP): Project framework, P. Natl. Acad. Sci., 111, 3228-3232, 2014.

Watanabe, S., Hirabayashi, Y., Kotsuki, S., Hanasaki, N., Tanaka, K., Mateo, C. M. R., Kiguchi, M., Ikoma, E., Kanae, S., and Oki, T.: Application of performance metrics to climate models for projecting future river discharge in the Chao Phraya River basin, Hydrol. Res. Lett., 8, 33-38, doi:10.3178/hrl.8.33, 2014.

Weedon, G. P., Gomes, S., Viterbo, P., Shuttleworth, W. J., Blyth, E., Österle, H., Adam, J. C., Bellouin, N., Boucher, O., and Best, M.: Creation of the WATCH Forcing Data and Its Use to Assess Global and Regional Reference Crop Evaporation over Land during the Twentieth Century, J. Hydrometeorol., 12, 823-848, doi:10.1175/2011JHM1369.1, 2011.

Weedon, G. P., Balsamo, G., Bellouin, N., Gomes, S., Best, M. J., and Viterbo, P.: The WFDEI meteorological forcing data set: WATCH Forcing Data methodology applied to ERAInterim reanalysis data, Water Resour. Res., 50, 7505-7514, doi:10.1002/2014WR015638, 2014.

Wei, Y., Liu, S., Huntzinger, D. N., Michalak, A. M., Viovy, N., Post, W. M., Schwalm, C. R., Schaefer, K., Jacobson, A. R., Lu, C., Tian, H., Ricciuto, D. M., Cook, R. B., Mao, J., and Shi, X.: The North American Carbon Program Multi-scale Synthesis and Terrestrial Model Intercomparison Project - Part 2: Environmental driver data, Geosci. Model Dev., 7, 2875-2893, doi:10.5194/gmd-7-2875-2014, 2014.

$\mathrm{Xu}, \mathrm{L}$. and Dirmeyer, P.: Snow-atmosphere coupling strength in a global atmospheric model, Geophys. Res. Lett., 38, L13401, doi:10.1029/2011GL048049, 2011.
Xu, L. and Dirmeyer, P.: Snow-Atmosphere Coupling Strength. Part II: Albedo Effect Versus Hydrological Effect, J. Hydrometeorol., 14, 404-418, doi:10.1175/JHM-D-11-0103.1, 2012.

Xu, L., Myneni, R. B., Chapin III, F. S., Callaghan, T. V., Pinzon, J. E., Tucker, C. J., Zhu, Z., Bi, J., Ciais, P., Tommervik, H., Euskirchen, E. S., Forbes, B. C., Piao, S. L., Anderson, B. T., Ganguly, S., Nemani, R. R., Goetz, S. J., Beck, P. S. A., Bunn, A. G., Cao, C., and Stroeve, J. C.: Temperature and vegetation seasonality diminishment over northern lands, Nat. Clim. Change, 3, 581-586, 2013

Yoshimura, K. and Kanamitsu, M.: Dynamical Global Downscaling of Global Reanalysis, Mon. Weather Rev., 136, 2983-2998, doi:10.1175/2008MWR2281.1, 2008.

Yoshimura, K. and Kanamitsu, M.: Incremental Correction for the Dynamical Downscaling of Ensemble Mean Atmospheric Fields, Mon. Weather Rev., 141, 3087-3101, doi:10.1175/MWR-D-1200271.1, 2013.

Zampieri, M. and Lionello, P.: Anthropic land use causes summer cooling in Central Europe, Clim. Res., 46, 255-268, 2011.

Zampieri, M., Serpetzoglou, E., Anagnostou, E. N., Nikolopoulos, E. I., and Papadopoulos, A.: Improving the representation of river-groundwater interactions in land surface modeling at the regional scale: Observational evidence and parameterization applied in the Community Land Model, J. Hydrol., 420-421, 7286, doi:10.1016/j.jhydrol.2011.11.041, 2012.

Zampieri, M., Scoccimarro, E., Gualdi, S., and Navarra, A.: Observed shift towards earlier spring discharge in the main Alpine rivers, Sci. Total Environ., 503-504, 222-232, doi:10.1016/j.scitotenv.2014.06.036, 2015.

Zhang, Y., Wood, E. F., Pan, M., Sheffield, J., Siemann, A., Fisher, C., Liang, M., Beck, H., MacCracken, R., Houser, P., Zhou, T., Lettenmaier, D. P., Pinker, R. T., Bytheway, J., and Kummerow, C. D.: A Climate Data Record (CDR) for the global terrestrial water budget: 1984-2010, J. Climate, submitted, 2016.

Zscheischler, J., Orth, R., and Seneviratne, S. I.: A submonthly database for detecting changes in vegetationatmosphere coupling, Geophys. Res. Lett., 42, 9816-9824, doi:10.1002/2015GL066563, 2015. 